\title{
Analysis of rockfalls by means of a fractal fragmentation model
}

\author{
Ruiz-Carulla R \& Corominas J \\ Division of Geotechnical Engineering and Geosciences \\ Department of Civil and Environmental Engineering. Universitat Politècnica de Catalunya- \\ BarcelonaTech \\ roger.ruiz@upc.edu
}

\begin{abstract}
:
We present the performance of the rockfall fractal fragmentation model (RFFM) developed by Ruiz-Carulla et al. (2017) and based on Perfect (1997). The RFFM combines disaggregation of the initial rock mass and breakage of the blocks. The model has been upgraded as to meet the mass balance, and to generate both a continuous decreasing and scale variant distribution of fragments volumes. The input of the model may be either a single block or a rock mass characterized by its In situ Block Size Distribution (IBSD). The measured fragment size distributions of seven inventoried rockfall events, are used to calibrate the model. The results of the simulations fit well to the measured volume distributions. Our findings indicate that fragmentation is better characterized by the whole volume distribution of fragments generated and the increase of new surface area of the rock fragments. A relation has been observed between the potential energy of the first impact, the new surface area of fragments generated, and the model parameters. Although a greater number of parametric analyses and calibration exercises are required, this relation is proposed as a first approach to model rockfall scenarios.
\end{abstract}

Keywords: rockfall, fragmentation model, rockfall inventory, fragmental rockfall, block size distribution. 


\section{Notations and nomenclature:}

IBSD In situ Block Size Distribution.

RBSD Rockfall Block Size Distribution.

RFFM Rockfall Fractal Fragmentation Model.

$\boldsymbol{k} \quad$ Number of initiators blocks.

b Geometrical factor.

$i \quad$ Level of hierarchy in a fractal system. Number of iteration in numerical solutions.

$\boldsymbol{b}^{i} \quad$ Geometrical factor to the power at $i^{\text {th }}$ level of hierarchy.

$N\left(\mathbf{I} / \boldsymbol{b}^{i}\right)$ Total number of fragments at the $i^{\text {th }}$ level of hierarchy.

$\mathbf{1} / \boldsymbol{b}^{i} \quad$ Fragment size descriptor in function of the geometrical factor and the $i^{\text {th }}$ level of hierarchy in a fractal system.

$\boldsymbol{n}_{\boldsymbol{i}} \quad$ Number of fragments generated only in the $i^{\text {th }}$ level of hierarchy.

D Fractal dimension.

$\boldsymbol{P}\left(\mathbf{1} / \boldsymbol{b}^{i}\right)$ Probability of failure at the $i^{\text {th }}$ level of hierarchy.

Sr Survival rate.

$V_{\min } \quad$ Minimum volume threshold value for fragments generation.

$\boldsymbol{q} \quad$ Probability of survival.

$r \quad$ Scale variance factor.

$\boldsymbol{l}_{\max } \quad$ Length of the largest fragment generated from each initiator block.

$l \quad$ Length of each new fragment generated from each initiator block.

$\left(\boldsymbol{l}_{\max } / \boldsymbol{l}\right)$ Fragments size descriptor in function of the length of the largest fragment generated and the length of each fragment generated from each initiator block.

$\boldsymbol{P}\left(\boldsymbol{l} / \mathbf{I}_{\max }\right)$ Probability of failure of blocks of $\left(I / l_{\max }\right)$ size.

$\boldsymbol{X i}_{\boldsymbol{r}}{ }^{2} \quad$ Reduced Chi squared test error estimator.

$n \quad$ Number of fragments accumulated.

Vo Volume of the initiator block.

DFN Discrete Fracture Network.

DSM Digital Surface Model. 3D mesh format.

$\boldsymbol{U A} \boldsymbol{V}$ Unmanned Aerial Vehicle. 
Dmin Minimum Fractal Dimension.

Dmax Maximum Fractal Dimension.

Pmin Minimum Probability of Failure.

Pmax Maximum Probability of Failure.

RMR Rock Mass Rating.

UCS Uniaxial Compressive Strength.

TS Tensile Strength

$I_{3 \boldsymbol{D}}$ Initial Area based on 3D surfaces of the 3D blocks in mesh format, measured in $\mathrm{m}^{2}$. Sum of all the surfaces of the IBSD blocks.

IA $\boldsymbol{A}_{\text {cubic }}$ Initial Area based on the 3D surface of a cubic estimation of blocks, measured in $\mathrm{m}^{2}$. Sum of all the surfaces of the IBSD blocks.

TA Total Area, measured in $\mathrm{m}^{2}$. Sum of all the fragments surfaces in the deposit.

$\boldsymbol{T A}_{\boldsymbol{R} \boldsymbol{B} S \boldsymbol{D}}$ Total Area based on the RBSD blocks, measured in $\mathrm{m}^{2}$. Sum of all the fragments surfaces in the rockfall deposit.

$\boldsymbol{T A}_{\boldsymbol{R} F \boldsymbol{F} \text { M }}$ Total Area based on the RFMM blocks (proposed model output), measured in $\mathrm{m}^{2}$. Sum of all the fragments surfaces in the rockfall deposit.

NA New Area, measured in $\mathrm{m}^{2}$. Defined as the difference between the Initial Area and the Total Area.

$\boldsymbol{N A}_{\boldsymbol{R} \boldsymbol{B S D} \boldsymbol{D}}$ New Area based on the RBSD blocks, measured in $\mathrm{m}^{2}$. Defined as the difference between the Initial Area and the Total Area based on the RBSD blocks.

NA $A_{\text {RFFM }}$ New Area based on the RBSD blocks, measured in $\mathrm{m}^{2}$. Defined as the difference between the Initial Area and the Total Area based on the RFFM blocks.

SSA Specific Surface Area, measured in $\mathrm{m}^{-1}$. Amount of surface area per unit volume of an object or collection of objects, also defined as surface-area-to-volume ratio.

ISSA Initial Specific Surface Area, measured in $\mathrm{m}^{-1}$. IA normalized by the total rockfall volume. Descriptor of the initial state of the blocks detached from the cliff.

TSSA Total Specific Surface Area, measured in $\mathrm{m}^{-1}$. TA normalized by the total rockfall volume. Descriptor of the final state of the fragments in the rockfall deposit.

NSSA New Specific Surface Area, measured in $\mathrm{m}^{-1}$. NA normalized by the total rockfall volume. Descriptor of the new surface area per unit of volume generated by breakage. 


\section{Introduction:}

Fragmentation of the rock mass is the reduction in particle size due to an external action. It is of interest in mining industry, particularly for the activities of drilling and blasting because it affects the cost of excavation and loading operations. An efficient blasting should avoid secondary blasting or mechanical breakage of the rock fragments (Aler et al. 1996; Morin et al. 2006; Kulatilake et al. 2010; Sanchidrián et al. 2014). Rock fragmentation is relevant for the performance and efficiency of mechanical excavators, tunnel boring machines, and the consumption of cutting tools (Gong et al. 2005; Bakar et al. 2014). In nature, rock fragmentation is found associated to the collision of meteorites, asteroids and interstellar grains (Hartman, 1969; Keil et al. 1994), the emplacement of volcanic deposits (Wohletz et al. 1989; Bonadona and Houghton, 2005), or as result of the tectonic activity (Molnar et al. 2007; Sammis and King, 2007). Fragmentation also occurs during the emplacement of rock avalanche deposits (Locat et al. 2006; Crosta et al. 2007; Davies et al. 1999; Hewitt, 1999; Weidinger et al. 2014) and in rockfalls (Giacomini et al. 2009, Wang and Tonon 2010, Crosta et al. 2015).

Despite the increasing number of studies on rockfalls, fragmentation as consequence of the impact on the ground surface is poorly understood. The rock volume detached from a cliff consists of either an individual block or a jointed rock mass. In the latter, the intersection of joints defines individual blocks, which range of sizes is the In-situ Block Size Distribution (IBSD) (Lu and Latham, 1999; Elmouti and Poropat, 2012). As the result of the impact, the rockfall fragments appear scattered along the slope and, as the rockfall volume increases, a more or less continuous debris cover is formed. The range of sizes of the rockfall fragments is the Rockfall Block Size Distribution (RBSD). Davies et al. (1999) restricted fragmentation to the breakage of rocks into pieces smaller than those defined by the joint system of the parent rock mass. Here, we use fragmentation as a generic and inclusive term, meaning the division of an initial rock block or rock mass caused by either the breakage of the rock pieces, the disaggregation of joint-determined blocks, or both (Ruiz-Carulla et al. 2017).

The quantitative hazard and risk analyses of rockfalls requires the quantification of fragmentation. The impact of the rockfall mass upon the ground surface results in the production of a number of smaller pieces that move as independent rigid bodies, with different velocities, and often divergent trajectories. Because of this, fragmentation affects both the runout and energy of the new particles (Agliardi and Crosta, 2003) and the encounter probability with the elements at risk (Corominas et al, 2019). Rockfall analyses based on the assumption of large unbroken rockfall masses will produce unrealistic results (Okura et al. 2000; Dorren 2003).

The analysis of the rockfall fragmentation has been approached empirically by means of real scale tests (Giacomini et al. 2009; Gili et al. 2016), and in the laboratory (Bowman and Take, 2015). The results showed the complexity in predicting the size distribution of the fragments based on impact energy thresholds of individual rock blocks. On the other hand, numerical simulations with Discrete Elements Methods highlight that high kinetic energy associated to steep slopes increases the intensity of fragmentation (Zhao et al. 2017). 
Editorial version: https://link.springer.com/article/10.1007/s00603-019-01987-2

Perfect (1997), described fragmentation as a natural phenomenon that may be characterized by means of fractals. In the present paper we present the performance of the fractal fragmentation model of Ruiz-Carulla et al. (2017), that simulates the processes of disaggregation and breakage in rockfalls by means of the calibration of 7 inventoried fragmental rockfalls. The model has been upgraded with the inclusion of the scale variant equations and considering the cumulative number of fragments proposed by Perfect (1997). We present the basic components of the model and improvements in section 2, the simulation of seven inventoried rockfall cases in section 3, and the results and discussion in section 4.

\section{Modelling the fractal behavior of Rockfalls}

\subsection{Fragmentation metrics}

Several descriptors have been proposed to quantify fragmentation. The mean size or the diameter before (D) and after (d) breakage has been used in the mining industry (Cunningham, 1987; Hardin 1985), which has been related with the explosive energy and powder factors (Kuznetsov, 1973). This type description means that the rock mass redistribution after fragmentation is described using an average size of the fragments. To complement it, a shape coefficient for the whole distribution may be included (Hou et al. 2017). In fact, the mean size and the uniformity coefficient are parameters required to obtain statistical distributions, which can be fitted to the rock fragments distributions. The approach most commonly used in blasting activities is the Rosin-Ramler model (Latham et al. 2006, Gheibie et al. 2009, Kulatilake et al. 2010 and Hudaverdi et al. 2010). Similarly, the largest remaining fragment has been suggested as descriptor of the fragmentation intensity (Bowman et al, 2014; Haug et al, 2016).

For those interested in rockfall hazard and risk analyses, we argue that these descriptors are not enough. To illustrate it, two synthetic cases with the same largest remaining fragment but different block size distribution are shown in Figure 1 and 2. The rock block with a volume of $0.67 \mathrm{~m}^{3}$, breaks upon impact on the ground generating 3 (Figure 1a) and 10 (Figure 1b) fragments. The largest remaining fragment has $0.38 \mathrm{~m}^{3}$ in both cases but block in Figure 1b generates more fragments and different range of volumes. The total surface area of the initiator block has a 3D surface of $4.5 \mathrm{~m}^{2}$, and the total surface area of the fragments increases from 6.6 $\mathrm{m}^{2}$ to $8.33 \mathrm{~m}^{2}$, respectively (Figure 2). This has a direct effect in rockfall hazard assessment. The knowledge of the number and size of the rockfall fragments are required in order to quantify the trajectories, runout distances and energies of the fragments, the impact probabilities with the exposed objects and the efficiency of the protection measures. 


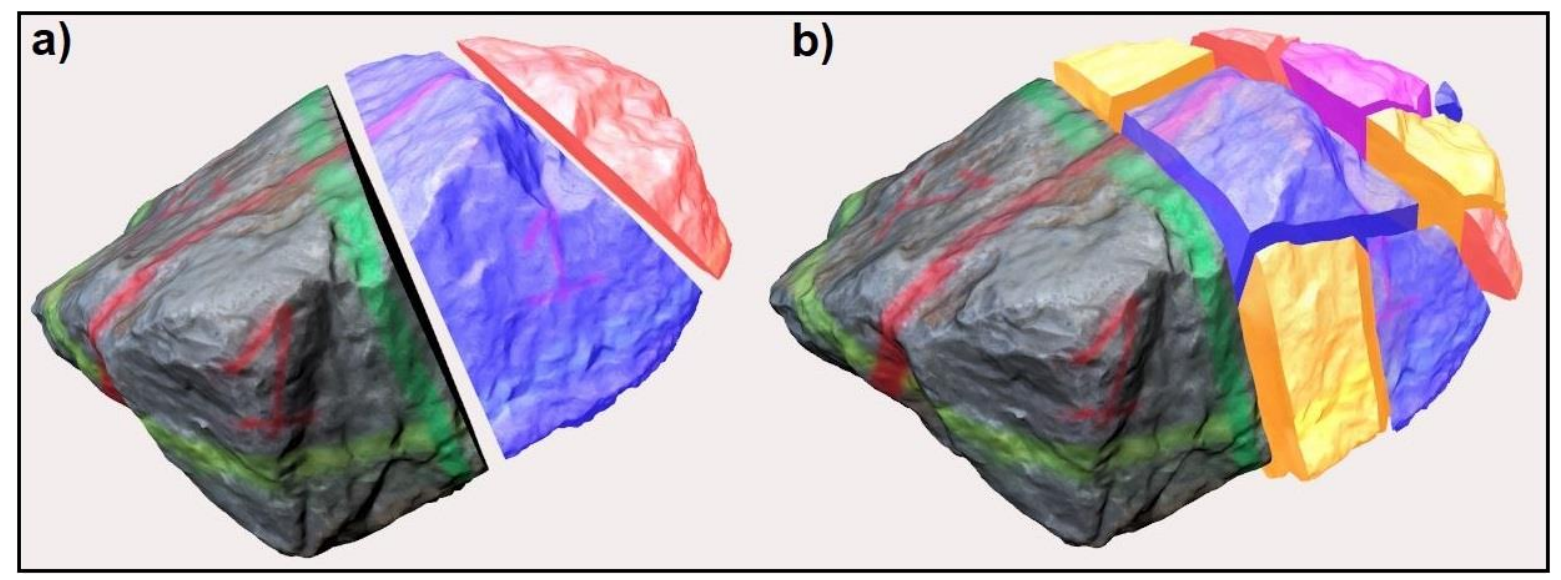

Figure 1: Comparison of two synthetic cases with the same probability of survival of the block and different number of fragments.

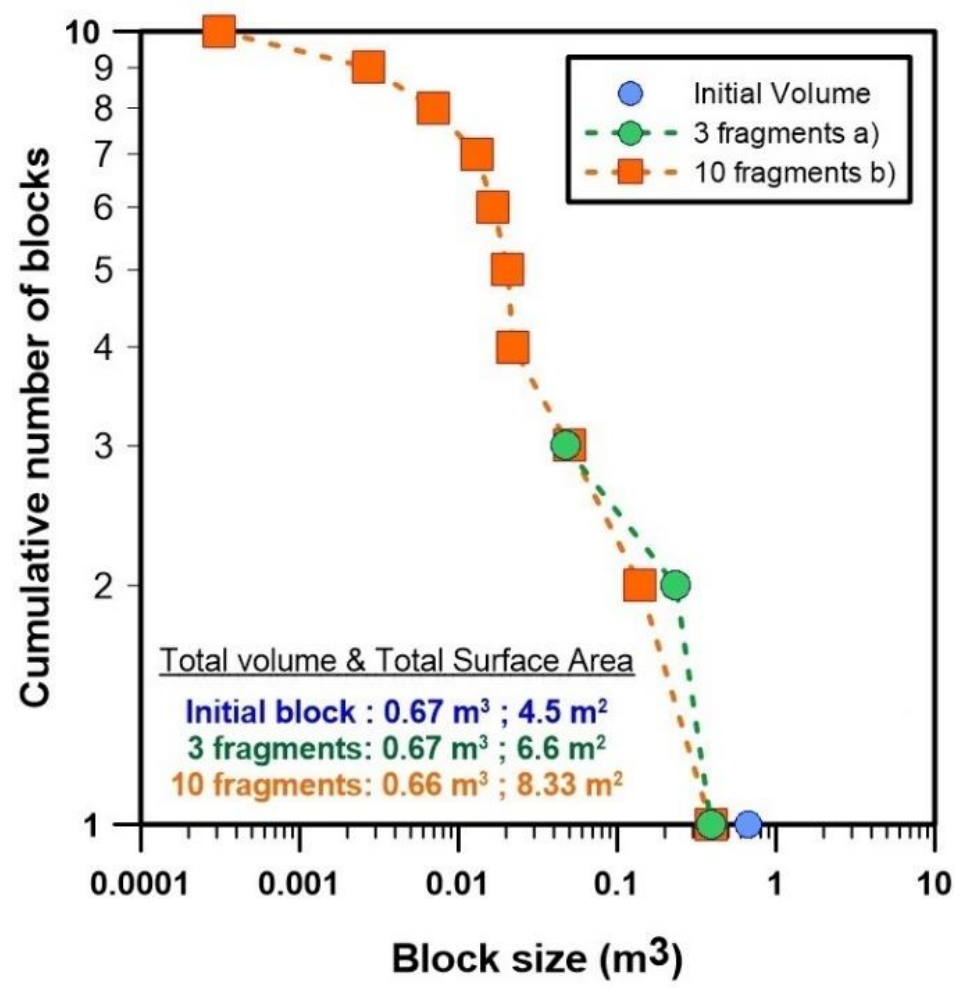

Figure 2: Comparison of two RBSD from synthetic cases (Figure 1, $a$ and $b$ ). Note the increase on total block surface from $4.5 \mathrm{~m}^{2}$ to $6.6 \mathrm{~m}^{2}$ and $8.33 \mathrm{~m}^{2}$.

Fragmentation of a rockfall may be therefore quantified by comparing the block size distributions before (IBSD) and after (RBSD) the impact on the ground (Charrière et al. 2015; Ruiz-Carulla et al. 2017) (see Figure 3). 

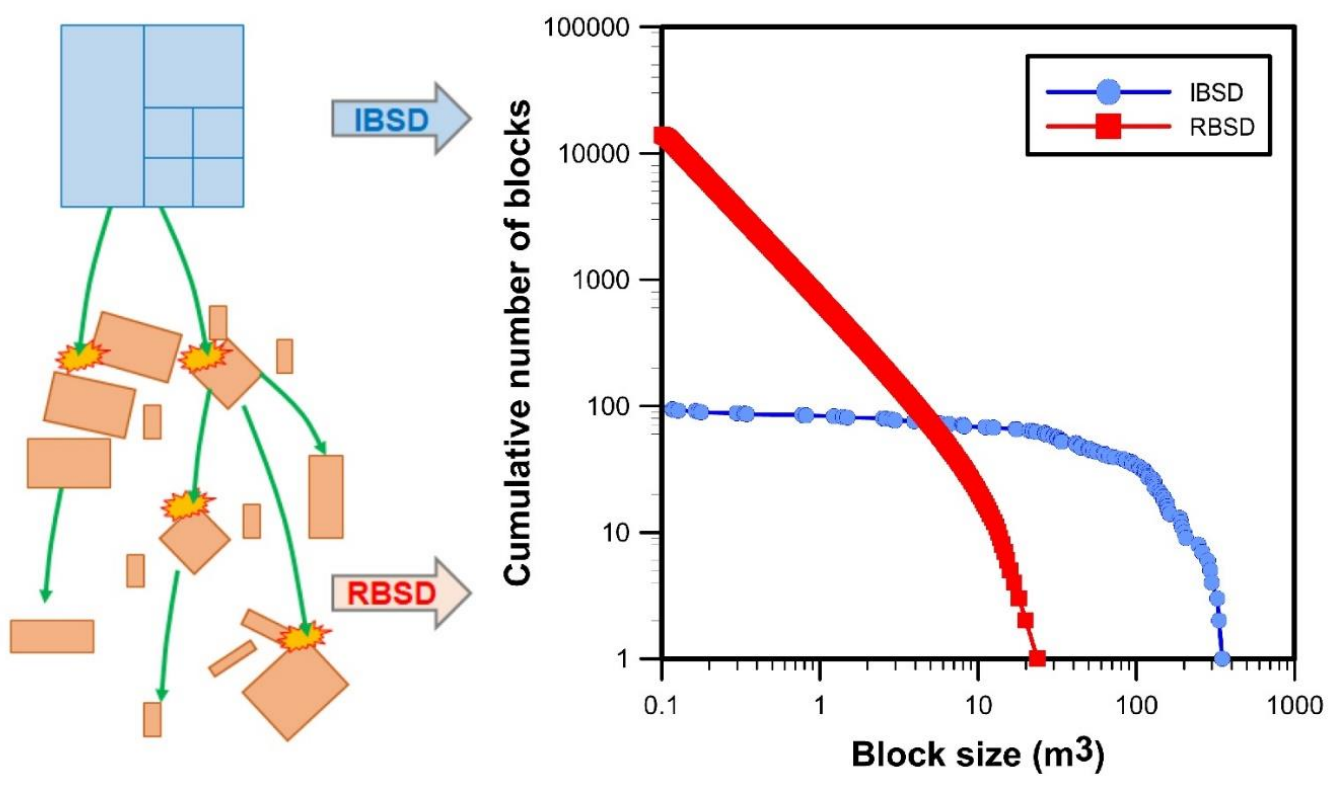

Figure 3: Change in block volume distribution by fragmentation. The initial block size distribution (IBSD) results in an increase of the number of blocks by fragmentation (RBSD).

\subsection{The Rockfall Fractal Fragmentation Model}

The Rockfall Fractal Fragmentation Model (RFFM) proposed by Ruiz-Carulla et al, 2017, takes the In situ Block Distribution (IBSD) as input and use 3 parameters to obtain Rockfall Block Size Distribution (RBSD). The model generates a block size distribution (RBSD) from a single block or a list of blocks (IBSD). Each broken block produces a distribution of fragments according to the main equation for fractal systems (Perfect, 1997), which is written as follows (Eq.1):

$$
N\left(1 / b^{i}\right)=k\left[1 / b^{i}\right]^{-D} ; i=0,1,2 \ldots \infty \quad \text { Eq. } 1
$$

Where " $N\left(1 / b^{i}\right)$ " is the total number of fragments at the $i^{\text {th }}$ level of hierarchy (or iterations); " $k$ " is the number of initiators of unit length, where initiators are the initial blocks as input; " $b$ " is the geometrical factor $(b>1)$; that defines a geometric fractal proportion between the original block and the generated fragments; and " $D$ " is the fractal dimension. As many fractal systems, the generation of elements is based on an iteration procedure that is controlled by the term " $i$ " referencing to the number of iteration. " $N$ " is rounded to the lower nearest integer. The fractal dimension $\mathrm{D}$ is defined by Eq. 2, where the probability of failure " $P\left(1 / b^{i}\right)$ " expresses the proportion of the block that breaks creating new fragments. Following the description of Perfect (1997), the probability of failure " $P\left(1 / b^{i}\right)$ " ranges between $b^{-3}<P\left(1 / b^{i}\right)<1$, and when $P\left(1 / b^{i}\right)=1$ and $D=3$, the whole block is fragmented, while for $P\left(1 / b^{i}\right) \leq b^{-3}$ the block remains intact.

$$
D=3+\frac{\log \left[P\left(1 / b^{i}\right)\right]}{\log [b]} \quad \text { Eq. } 2
$$


Editorial version: https://link.springer.com/article/10.1007/s00603-019-01987-2

In the RFFM presented in (Ruiz-Carulla et al. 2017), a survival rate ( $S r$ ) is included as percentage of blocks that remain intact (no breakage). For $S r=1$ pure disaggregation occurs. All the blocks survive and RBSD equals the IBSD. For $S r=0$, all blocks of the IBSD break, generating a new RBSD whose shape varies according to the fractal parameters considered in the model.

Three main drawbacks were identified with the performance of the RFFM: (1) The blocks of the IBSD (list of block volumes as input) are classified in bins according to their size (e.g. 0.1-0.5; 0.5-1; 1-5; 5-10; 10-50; 5 50$\left.100 \mathrm{~m}^{3}\right)$. Each block of the bin has the average volume of the bin instead of the exact one $\left(3 \mathrm{~m}^{3}\right.$ in the bin ranging between 1 and $5 \mathrm{~m}^{3}$ ). Because of this, the mass balance is not preserved; (2) Each iteration increases the number of fragments by reducing their size. However, the number of iterations used modifies the value of the fitted model parameters $P\left(1 / b^{i}\right)$ and $b$; (3) Finally, the model produces fragments of equal size in each iteration. However, experiments with single blocks falls (Gili et al. 2016) and the rockfall inventories show that the fragments generated follow continuous decreasing size distributions, which in some cases may not fit to a scale invariant behavior. This effect is masked when the initiator is an IBSD but becomes evident when the initiator is a single block.

To overcome the mentioned drawbacks we have upgraded the RFFM by adding the alternatives proposed in the paper of Perfect (1997). The iteration over the geometric factor " $b$ " which generates fragment volumes in terms of $\left(1 / b^{i}\right)$, is replaced by $(1 /$ max $)$ in a cumulative form, where "lmax" is the length of the largest remaining fragment, and "l" is the length of each new fragment generated. This procedure avoids iteration and prevents from obtaining equally sized fragments. Instead of using the average volume of the blocks in each bin, the procedure is applied to each initiator block. This is carried out by listing all the volumes of the IBSD. The resultant RBSD is a continuous list of rock fragments, which is described as cumulative number of fragments ordered by decreasing size. The steps of the procedure are shown in what follows.

In the upgraded RFFM, Eq.1 describing the number of fragments of size " $1 / b^{i}$ " is rewritten in terms of cumulative number of fragments of size greater than or equal to " $l / l_{\max }$ " (Eq. 3). As we apply the model over every block of the IBSD, the number of initiators is always $1(k=1)$.

$$
\mathbb{N}\left(l / l_{\max }\right)=\left[l / l_{\max }\right]^{-D}
$$

Eq. 3

The length " $l$ " of the fragments generated starts with " $l_{\max }$ ". Then " $l_{\max } / l_{\max }$ " is 1 , and the cumulative number of fragments for the largest fragment is 1 . Then, " $l$ " decreases giving " $N$ " accumulated number of fragments. As the number of fragments must be a natural number, the term "N$\left(l / l_{\max }\right)$ " is rewritten as a variable " $n$ ", ranging from 1 to infinite. Therefore, Eq. 3 may be rewritten as function of the number " $n$ " of fragments accumulated, obtaining the length " $l$ " that defines the size of the following fragment:

$$
l=l_{\max } \cdot n^{-1 / D} ; n=1,2 \ldots \infty \quad \text { Eq. } 4
$$


As " $l_{\max }$ " and " $l$ " only represent proportions, to convert the characteristics lengths " $l$ " into volumes, the initial volume "Vo" is used. Therefore, the main equation used to generate the cumulative number of fragment volumes in the upgraded model is:

$$
V_{\text {frag }}(n)=V_{o} \cdot l_{\max } \cdot n^{-1 / D} ; n=1,2 \ldots \infty \quad \text { Eq. } 5
$$

The maximum length " $l_{\max }$ " is defined as $l_{\max }=1-P\left(l / l_{\max }\right)$ in the scale invariant formulation (Perfect, 1997).

The generated RBSD is obtained increasing " $n$ " from 1 to infinite. The sequence of volume generation is as follows: first, the largest fragment, and then, the rest of fragments are added, ordered by decreasing sizes, until either the initial block volume is completed or until the fragments become smaller than the threshold defined. The threshold value is established as the minimum volume of the fragments generated $\left(\mathrm{V}_{\min }\right)$ that is not measured and checked in the field. The remaining mass below the threshold is computed as fine fraction.

The effect of the replacement of " $1 / b^{i}$ " by " $1 / 1_{\max }$ " and the use of the cumulative list of volumes instead of bins, is illustrated in Figure 4. The input of the model is, in both cases, the IBSD composed of a single block of $1 \mathrm{~m}^{3}$ (blue square in Figure 4). The models parameters are $b=2$ and $P\left(1 / b^{i}\right)=0.5$. The RBSD using " $1 / b^{i}$ " has three different sizes (purple squares in Figure 4). The results after two iterations are: a fragment of $0.5 \mathrm{~m}^{3}$, four fragments of $0.05 \mathrm{~m}^{3}$ each, and 16 fragments of $0.01 \mathrm{~m}^{3}$ each, being 21 in cumulative number of fragments $(1+4+16)$. In contrast, $1 / 1_{\max }$ " generates 7 fragments of different size (green dots in Figure 4). The sum of fragments volume using " $1 / b^{i}$ " is $0.86 \mathrm{~m}^{3}$, that is, a loss of $0.14 \mathrm{~m}^{3}$ of the initial mass. The sum of fragments volume using " $1 / 1_{\max }$ " is $0.999 \mathrm{~m}^{3}$, obtaining consistent results in terms of mass balance.

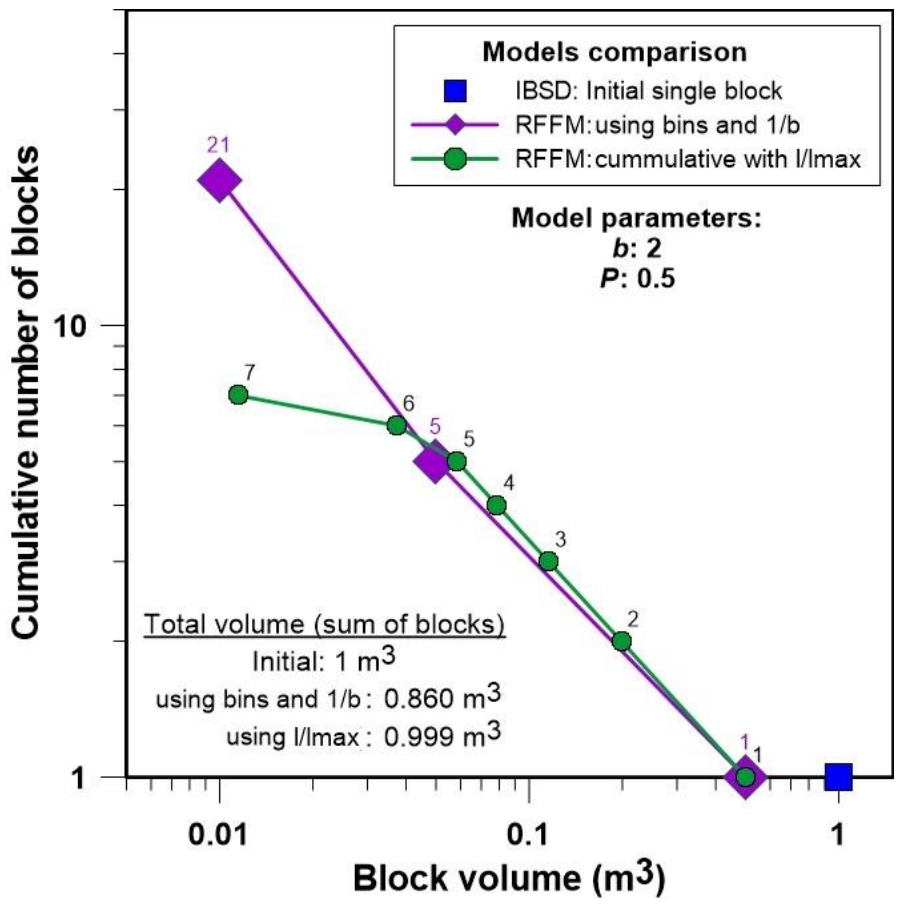

Figure 4: RFFM performance for breakage of $1 \mathrm{~m}^{3}$ using bins (two iterations and $1 / b^{i}$ as size descriptor), and using the cumulative form, and $l / l m a x$ as size descriptor. 


\subsection{Scale variant behavior}

As mentioned above, the measurement of more than 10.000 fragments in the 7 inventoried rockfalls and real scale fragmentation tests, indicate that fragments generated may follow either scale invariant or variant behavior. The latter is characterized by a change in the proportion between the number of objects and their size. The scale variant behavior implies the modification of the fractal dimensions depending on the objects size. Then, blocks distributions cannot be fitted with a simple power law. This is illustrated in Figure 5 showing the cumulative RBSD (red dots) of one of the real scale fragmentation test (Gili et al, 2016). The blue dot represents the initial volume of the block tested. The scale invariant volume distribution generated with the RFFM (green dots) diverges from the distribution of the small-fragments measured (Figure 5, left). The results of the model using the scale variant formulation (Figure 5, right) reproduces adequately the changes in the slope for the entire volume distribution.

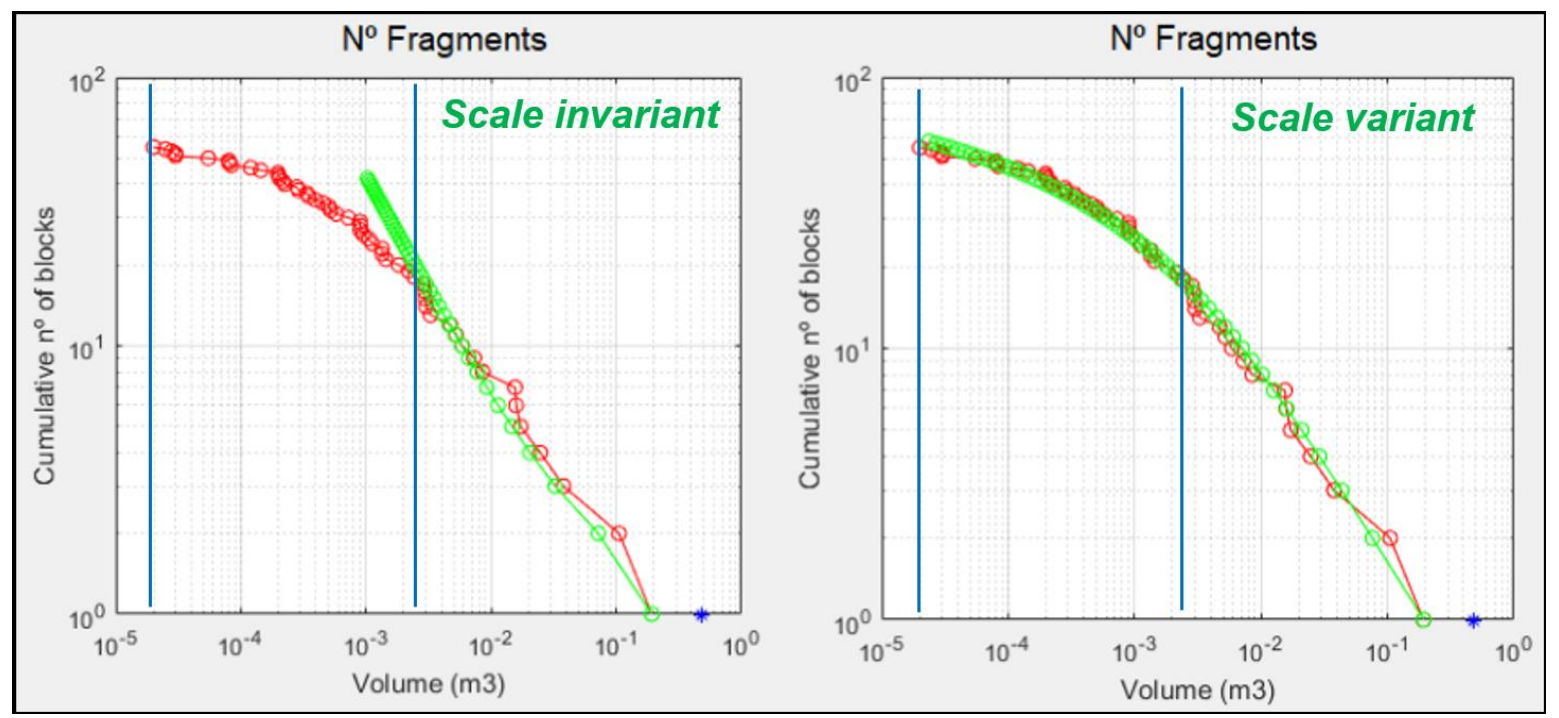

Fig. 5: Calibration of the RFFM (green dots) using the scale invariant (left), and the scale variant (right) formulations. The calibration is carried out by fitting the distribution to the measured RBSD (red dots) from the fragmentation test of a single block volume (blue dot).

In the case of scale variant behavior, the number of fragments generated changes with the scale. In this case, each block size has different probability of failure, in the form (Perfect, 1997):

$$
P\left(1 / b^{i}\right)=1-q\left(b^{i}\right)^{r} \quad \text { Eq. } 6
$$

Where " $q$ " is the probability of survival of the rock block as defined by Perfect (1997). The probability of survival " $q$ " is interpreted as the inverse of the probability of failure " $P$ ". The latter expresses the proportion of the block that breaks creating new fragments. Therefore, the probability of survival " $q$ " expresses the proportion of the block that survives and defines the largest fragment generated after breakage. As the model is applied to each initiator block, the survival rate " $S r$ " is replaced by " $q$ ". The parameter " $r$ " controls the scale variant behavior and is explained next. 
The fractal dimension for scale variant behavior is (Perfect, 1997):

$$
D=3+\frac{\log \left[b^{r}-q\left(b^{i}\right)^{r}\right]}{\log [b]} \quad \text { Eq. } 7
$$

In the scale variant, different sizes display different patterns of fragmentation. For instance, the smaller blocks may offer a greater resistance to breakage than larger blocks. The increase or decrease of the strength of the rock block as the block size diminishes is simulated with the negative or positive value of " $r$ ", respectively. For $r=0$, the scale variant is equal to the scale invariant case.

Finally, the maximum length " $l_{\max }$ " for the scale variant formulation is defined as (Perfect 1997):

$$
l_{\max }=q\left(b^{n}\right)^{r} \quad \text { Eq. } 8
$$

The upgraded RFFM can generate block size distributions of different shapes. Figure 6 shows the results of real-scale rockfall tests (Gili et al. 2016; Ruiz-Carulla et al. 2016b). For the sake of brevity, only four cases are plotted. These examples illustrate the capability of the RFFM to generate both irregular shape and continuous BSD distributions, using the scale variant behavior and the continuous generation of fragments $\left(1 / l_{\max }\right)$. The size of the block tested was measured with digital photogrammetry (blue circles in Figure 6). At each test, the block dropped from a height of 17 meters.

The RBSD of each test is plotted in Figure 6 (red squares). The model parameters are calibrated by minimizing the difference between the volumes measured and the simulated (green diamonds in Figure 6). We run the model until the values of the reduced Chi squared " $\mathrm{Xi}_{\mathrm{r}}{ }^{2}$ fall between $10^{\wedge-4}$ and $10^{\wedge-2}$. Under the same testing conditions, blocks with similar volume and mechanical properties display contrasting behavior. From a probability of survival of 0.97 and few fragments generated (Figure 6 upper left, T1-B5 case), to probability of survival of less than 0.4 and tens of fragments generated, sometimes with a progressively curved shape distribution (Figure 6 bottom, T1-B3 and T1-B2). It is worth noticing that by breaking less than $20 \%$ of the block volume ( $q=0.817$ ), more than 20 fragments can be easily generated (Figure 6, T1-B12). 

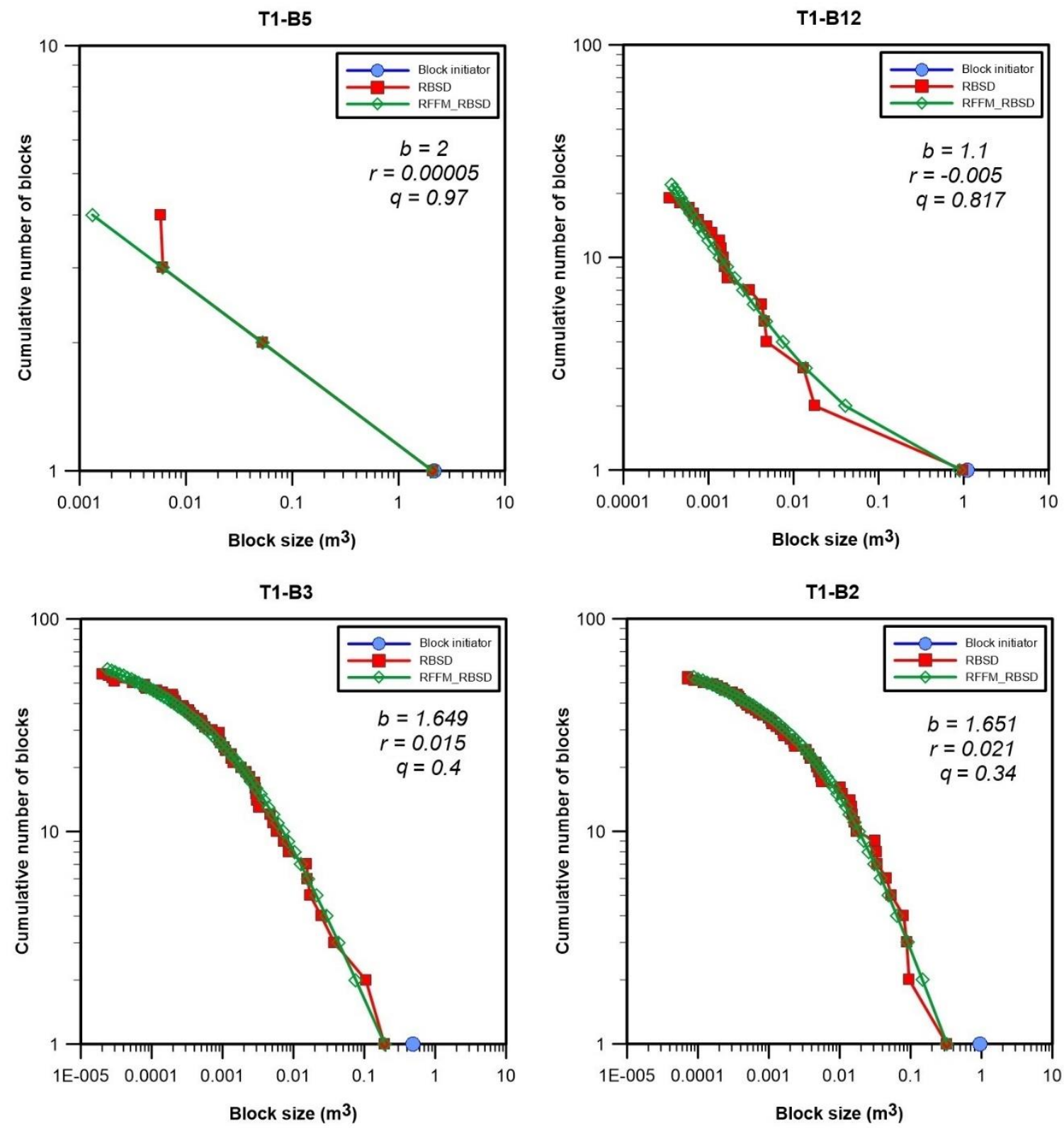

Figure 6: Results of a calibration of the model parameters with data from real-scale test. The block initiator size (blue circle); the measured RBSD (red squares), and modelled RFFM-RBSD (green diamonds) are shown.

\section{Performance of the RFFM}

Seven natural rockfall events have been simulated with the RFFM. The goals of the simulation are, on one side, testing the sensitivity of the parameters and calibrate the model considering different sizes, lithologies, rock strengths, heights of fall and slope conditions. On the other side, we aim at searching for relations between the model parameters and the geometry of the fall in order to adjust its predictive capacity. 
Editorial version: https://link.springer.com/article/10.1007/s00603-019-01987-2

\subsection{Inventoried rockfall events}

Perfect (1997) highlighted the need of using well detailed descriptions of the rigid bodies before and after the fragmentation. We present in this section the description and main characteristics of the block size distribution of 7 inventoried fragmental rockfalls. To characterize the initial state of the rock mass, we reconstructed the detached volume and the IBSD, the latter based on the joint pattern present on the cliff. This has been carried out using UAV and digital photogrammetry, obtaining the 3D model of the scar in point cloud format, and extracting the joint pattern on the cliff (Gates et al, 2012; Gigli and Casagli 2011; Haneberg et al, 2006; Buyer, et al 2017). On the other hand, the RBSD is obtained by measuring thousands of blocks in the rockfall deposit with a tape and following the procedure described in Ruiz-Carulla et al. (2015 and 2016a).

The seven rockfall events represent different scenarios, in terms of failure mechanism, lithology (limestone, sandstone, conglomerate and schist), volume (between $2 \mathrm{~m}^{3}$ and $10.000 \mathrm{~m}^{3}$ ), and impact ground conditions (Figure 7). Three rock samples of each event were collected for mineralogical description and rock strength testing. The description of the rockfall events and rock mass properties are summarized in Tables 1 and 2. 


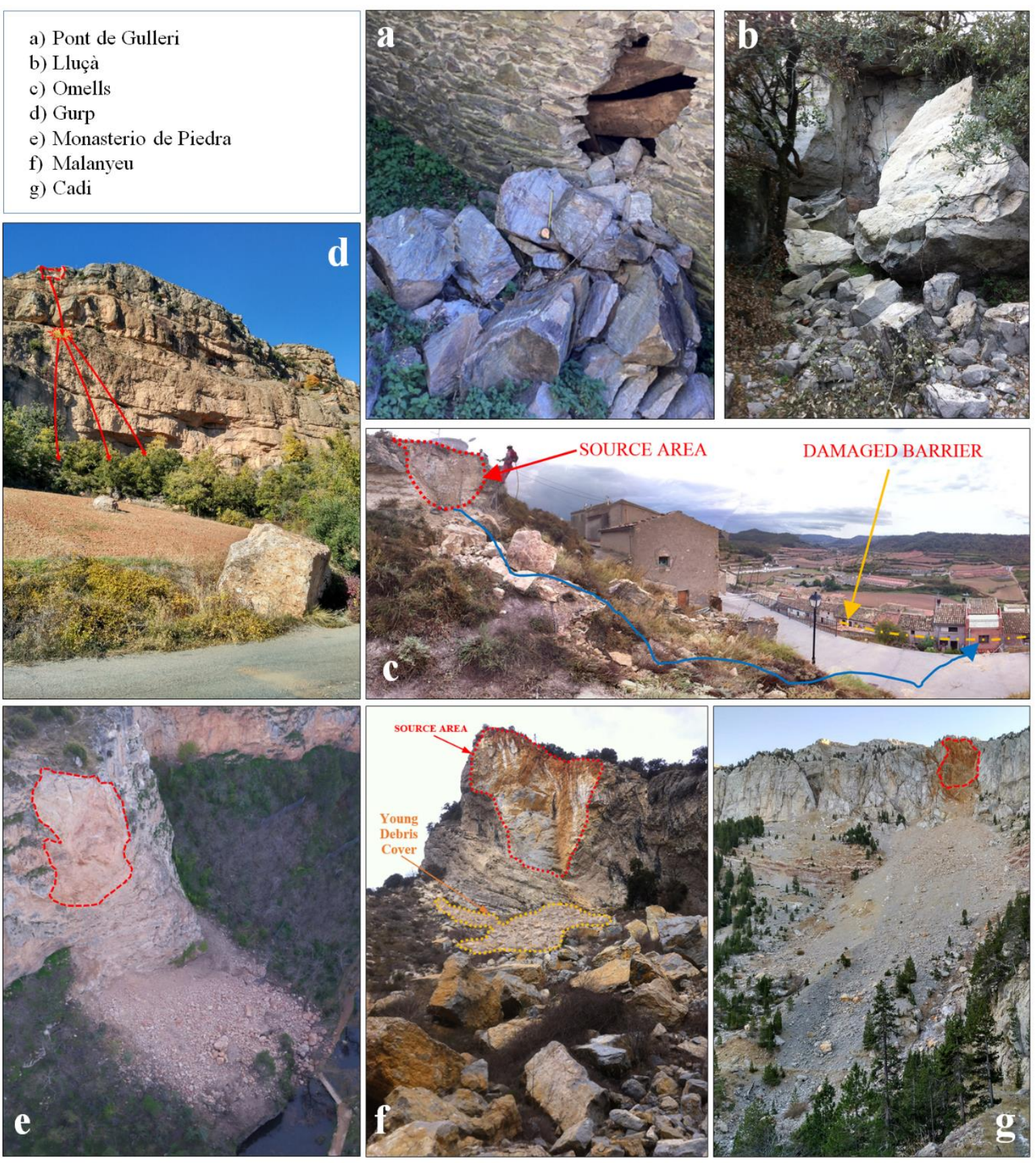

Figure 7: Pictures of the inventoried rockfalls. 
Editorial version: https://link.springer.com/article/10.1007/s00603-019-01987-2

Table 1: Rockfall inventory cases, summary data, rock properties and measured fragments.

\begin{tabular}{|c|c|c|c|c|c|c|c|}
\hline ROCKFALL & PdG & Omells & Lluca & Gurp & MdP & Malanyeu & Cadi \\
\hline Failure Mechanism & Slide & $\begin{array}{l}\text { Toe erosion } \\
\text { slide }\end{array}$ & Toppling & Toppling & $\begin{array}{l}\text { Toppling } \\
\text { Slide }\end{array}$ & Toppling & Slide \\
\hline Lithology & Schist & Sandstone & Sandstone & Conglomerate & Limestone & Limestone & Limestone \\
\hline Total Volume RBSD $\left(\mathrm{m}^{3}\right)$ & 2.6 & 4.2 & 10.7 & 100 & 900 & 4350 & 6351 \\
\hline Total Volume $\operatorname{IBSD}\left(\mathbf{m}^{3}\right)$ & 2.61 & 4.2 & 10.7 & 100 & 997 & 4945 & $7663^{*}$ \\
\hline RMR & 76 & 64 & 72 & 82 & 70 & 74 & 60 \\
\hline \multicolumn{8}{|l|}{ ROCK PROPERTIES } \\
\hline $\operatorname{Density}\left(\mathrm{kg} / \mathrm{cm}^{3}\right)$ & 2.72 & 2.35 & 2.46 & 2.69 & 2.5 & 2.64 & 2.68 \\
\hline Tensile Strength (MPa) & 6.53 & 2.03 & 2.07 & 5.47 & 10.00 & 7.03 & 12.10 \\
\hline UCS (MPa) & 32.17 & 21.38 & 21.77 & 38.36 & 35 & 13.33 & 35.29 \\
\hline E Young (MPa) & 17385 & 5185 & 730 & 74831 & 20000 & 12992 & 22761 \\
\hline Poisson ratio & 0.27 & 0.006 & 0.18 & 0.21 & 0.1 & 0.05 & 0.07 \\
\hline
\end{tabular}

\section{FRAGMENTS MEASURED}

\begin{tabular}{cccccccc}
\hline RBSD Total number blocks & 116 & 48 & 78 & 500 & 10790 & 28788 & 60980 \\
RBSD n of measured blocks & 116 & 48 & 78 & 500 & 2256 & 2721 & 1524 \\
Min. Measured Vol. $\left(\mathbf{m}^{\mathbf{3}}\right)$ & 0.0001 & 0.0007 & 0.0007 & 0.001 & 0.001 & 0.0001 & 0.01 \\
Max. Measured Vol. $\left(\mathbf{m}^{\mathbf{3}}\right)$ & 0.28 & 1.1 & 8.5 & 22 & 27 & 445 & 31
\end{tabular}

(*) recalculated volume that differs from Ruiz-Carulla et al (2015)

The images captured with UAV and the 3D photogrammetric reconstruction were used to measure distances reached by the blocks, the 2D (projected) and 3D areas of the deposits and their volumes, generate slope profiles with overhangs, and contour maps. Table 2 summarizes the main geometrical descriptors of the falls. The scar area is measured in the 3D model, obtaining a 3D surface area of the scar. The coefficient of correlation $\mathrm{r}$ squared of the 3D scar area and the total volume is 0.99 , using the lineal form "log(3DScarArea)" $=$ “log(TotalVolume)" $\cdot 0.4476+32.963$.

Table 2: Summary of geometrical descriptors of the falls measured on the 3D models:

\begin{tabular}{cccccccc} 
SCENARIO \& DEPOSIT & PdG & Omells & Lluca & Gurp & MdP & Malanyeu & Cadi \\
\hline Scar 3D Area (m $\mathbf{m}^{\mathbf{2}}$ & 9.55 & 15 & 32 & 87 & 578 & 2120 & 3532 \\
Cliff Height (m) & 15 & 3.3 & 6.8 & 100 & 50 & 70 & 150 \\
1st Impact Height (m) & 12 & 1 & 0.6 & 39 & 35 & 10 & 50 \\
CoG Height (m) & 13 & 5 & 2.8 & 110 & 60 & 80 & 230 \\
Total Fall Height (m) & 13 & 14.5 & 6.6 & 150 & 70 & 100 & 520 \\
Max. Runout (m) & 5 & 22 & 9.2 & 152 & 70 & 130 & 710 \\
Max. Volume Runout (m) & 5 & 3 & 5.6 & 152 & 40 & 80 & 200 \\
Reach Angle (degrees) & 69 & 33 & 36 & 45 & 45 & 38 & 36 \\
Deposit Width (m) & 2.5 & 15 & 5 & 40 & 50 & 80 & 130 \\
Deposit Area(m $\left.\mathbf{m}^{\mathbf{2}}\right)$ & 5 & 300 & 45 & 2000 & 4200 & 6000 & 44000
\end{tabular}


The falling rock mass tends to accelerate in the steepest part of the cliff $\left(>45^{\circ}\right)$ becoming the most "energetic part" of the trajectory (colored from yellow to red on 3D models of Figure 8). At Gurp (Figure 8, top), the slope profile shows a natural berm inclined less than $45^{\circ}$ (blue zone located at the upper half of the cliff). Rockfalls may impact over this berm, causing the breakage of the mass and redirecting the trajectories of the fragments. The gentle surfaces at the upper part of the cliff in Gurp and Monasterio de Piedra (Figure 8), define the base of the rockfall scar.

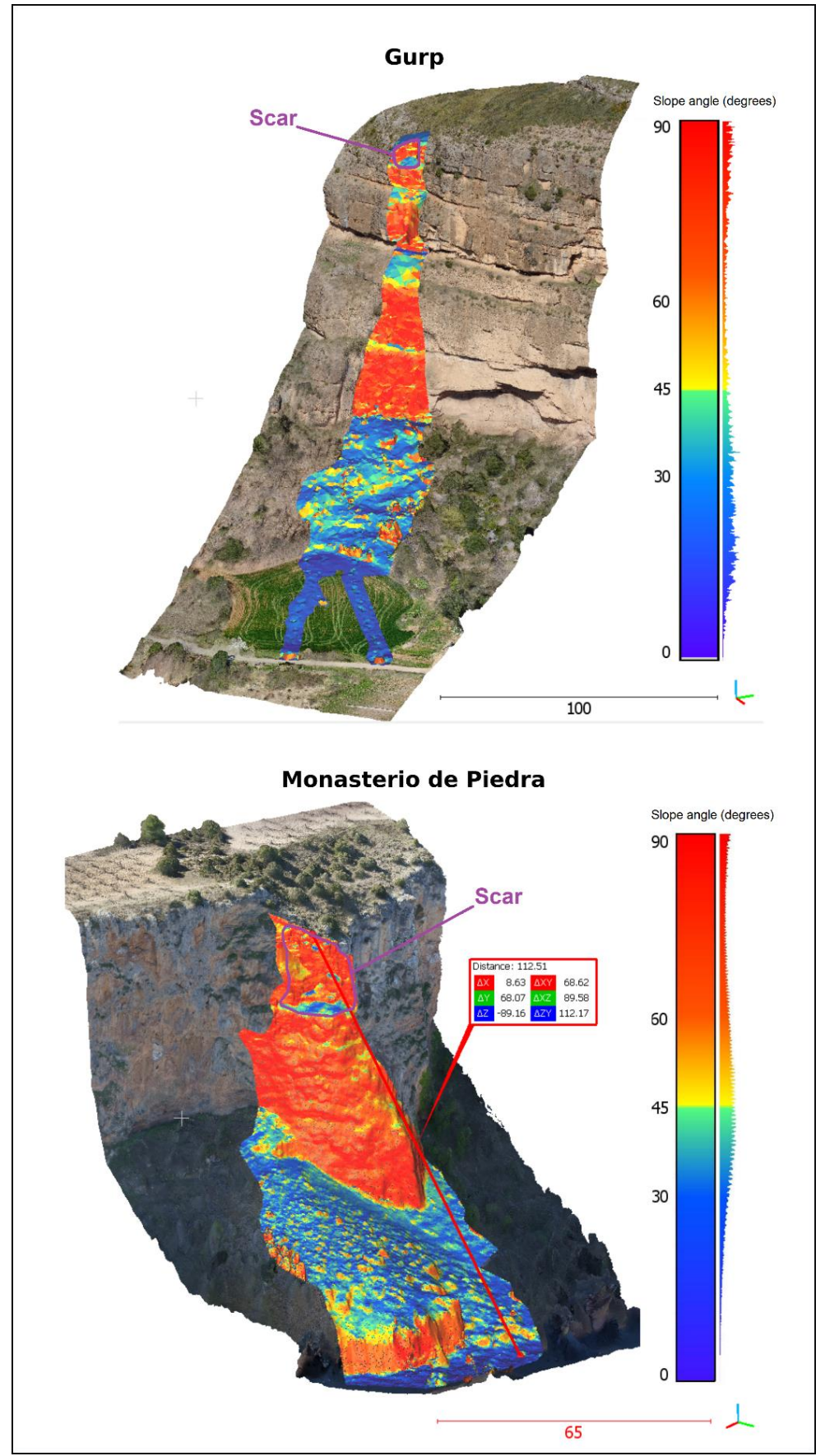

Figure 8: 3D models of Gurp and Monasterio de Piedra rockfalls. The zone affected by the rockfall is colored based on the slope surface angle. 
Editorial version: https://link.springer.com/article/10.1007/s00603-019-01987-2

\subsection{Reconstruction of the detached rock mass and generation of the IBSD}

The initiator of the fractal fragmentation model is the 3D reconstructed rock mass intersected by several discontinuity sets. The IBSD is generated by means of a discrete fracture network (DFN). The assumptions and procedures we have considered are described next.

The detached rockfall volume at each site is calculated as the difference of the Digital Surface Model (DSM, $3 \mathrm{~d}$ mesh surface) of the cliff before and after the event, following the methodology described in Ruiz-Carulla et al. (2015). The DSM prior to the event is generated from the LIDAR point cloud provided by the Cartographic and Geological Institute of Catalonia (ICGC), except for the case of Monasterio de Piedra, which is provided by the National Geographic Institute of Spain. When the morphology of the cliff and/or pictures before the event are not available, we manually modified the DSM in order to define the pre-event scenario as real as possible. The DSM of the cliff after the event is generated from the pictures taken using a UAV (DJI Inspire 2, X5S camera), except in the case of Vilanova de Banat that was obtained from ground pictures taken with a Nikon D90 camera.

The Facet Matching plugins (Dewez et al., 2016) on Cloud Compare (Girardeau-Montaut 2006) and Compass tool (Thiele et al. 2017) are applied to the 3D point cloud to extract semi-automatically the joint pattern of the cliff. The parameters of the Facet Matching used to define the fitted facets are accommodated to the scale of the main joint sets. Thus, in the definition of large facet areas, high tolerances are accepted for the minimum distance between the $3 \mathrm{~d}$ points and the facet planes. The fitting parameters are calibrated according to the scale of each rockfall scar, and the results are visually checked. The manual selection of the planes, the adjustment to the facets, as well as the identification of the joint traces is carried out using the Compass tool. Finally, the Discrete Fracture Network (DFN) is obtained by combining both semi-automatic and manual detection of joints, and exported as mesh format (Firpo et al., 2011). The DFN is overlaid to the volume of the detached rock mass to generate the IBSD using the software Rhinoceros ${ }^{\circledR}$. Joints are assumed fully persistent and are placed in its real position, thus providing the actual spacing. A few examples of the procedure followed are shown in Figure 9.

The blocks of the IBSD are listed and both the volume and the 3D surface area of each block are measured. The list of volumes is the input of the fragmentation model. Table 3 presents the main characteristics of the IBSD of the inventoried rockfall events 
Editorial version: https://link.springer.com/article/10.1007/s00603-019-01987-2

Table 3: Summary of IBSD characteristics:

\begin{tabular}{cccccccc} 
IBSD & PdG & Omells & Lluçà & Gurp & MdP & Malanyeu & Cadi \\
\hline N $^{\circ}$ of joint sets & 5 & 3 & 4 & 5 & 5 & 4 & 5 \\
IBSD Total number of blocks & 40 & 3 & 5 & 14 & 19 & 95 & 6800 \\
Min. Block Volume $\left(\mathrm{m}^{3}\right)$ & 0.0001 & 0.0007 & 0.0007 & 0.0015 & 0.001 & 0.0015 & 0.01 \\
Max. Block Volume $\left(\mathrm{m}^{3}\right)$ & 0.28 & 4 & 10.7 & 30 & 96 & 492 & 45 \\
Min joint spacing & 0.3 & 0.2 & 2 & 0.5 & 1 & 3 & 1
\end{tabular}

The 3D model of the scars shows the different orientation of the surfaces involved. The reconstructed volumes cut with the DFN of Gurp, Monasterio and Malanyeu cases are shown in Figure 9. The Cadí case is presented in Ruiz-Carulla et al (2017), following the same methodology. 


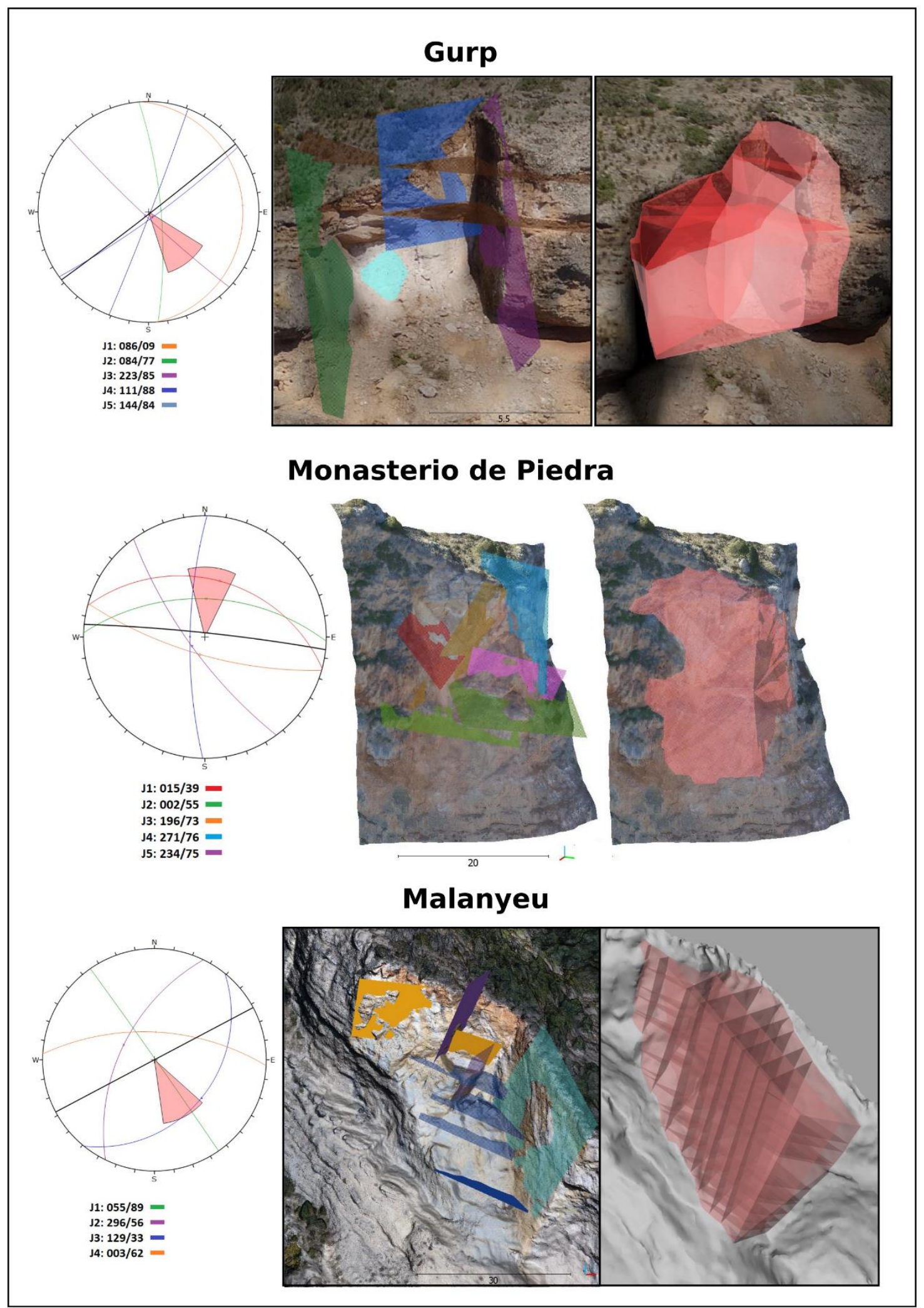

Figure 9: Stereoplots of the joint sets identified on the 3D models of the rockfall scar. The joint sets are overlaid to the detached volumes to generate the IBSD of Gurp, Monasterio and Malanyeu events. 


\subsection{Calibration of the model}

Here, each rockfall event is calibrated using the same set of parameters " $b$ ", " $r$ " and " $q$ " for all the blocks. The simulated block size distribution of fragments (RFFM_RBSD) is fitted to the measured (RBSD) (Figure 10 and Figure 11).
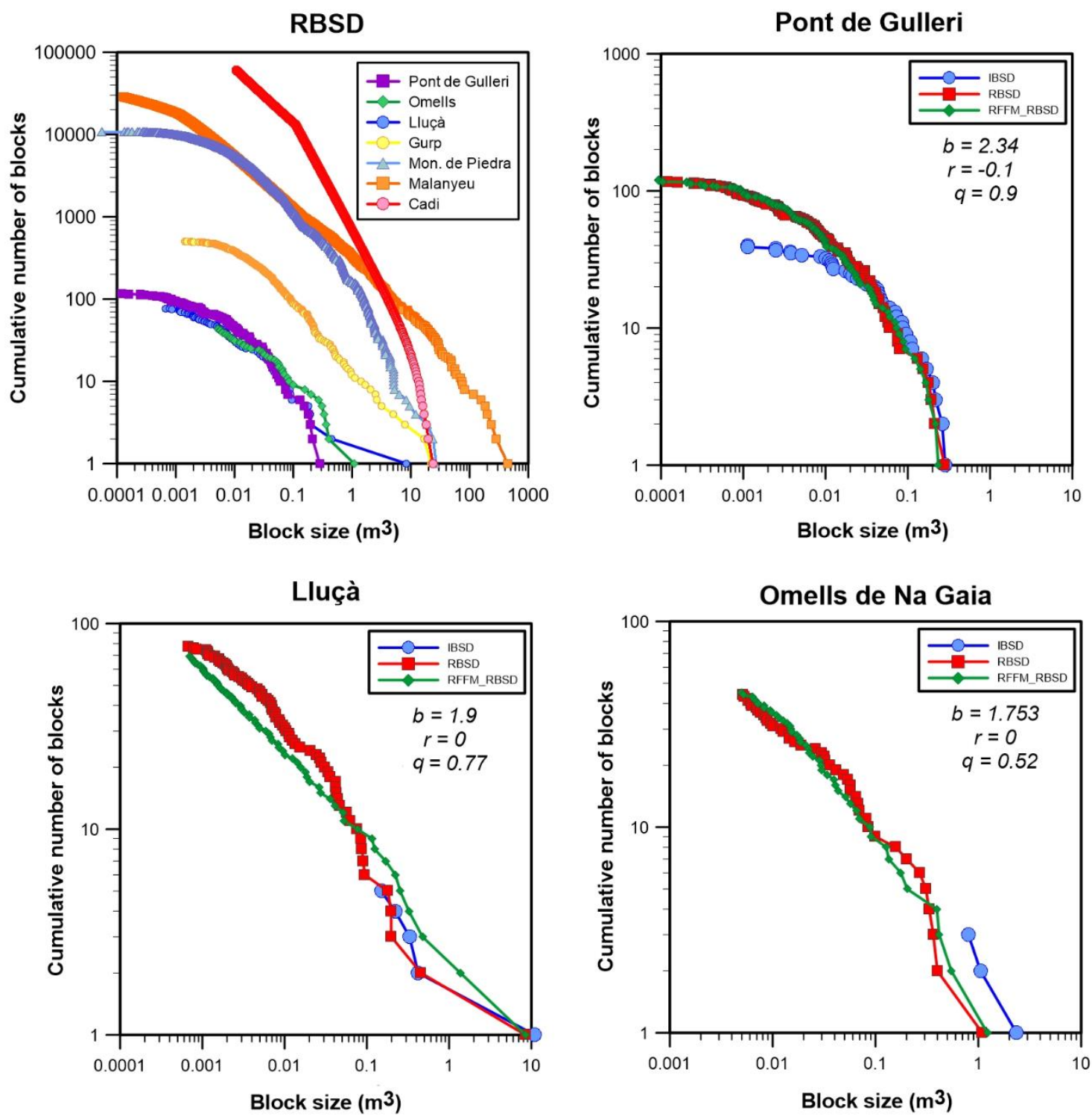

Figure 10: RBSD measured in the field (upper left) and performance of the RFFM. The RFFM is applied to the IBSD of Pont de Gulleri, Lluçà, and Omells rockfalls to generate the simulated fragment distributions (RFFM_RBSD). 

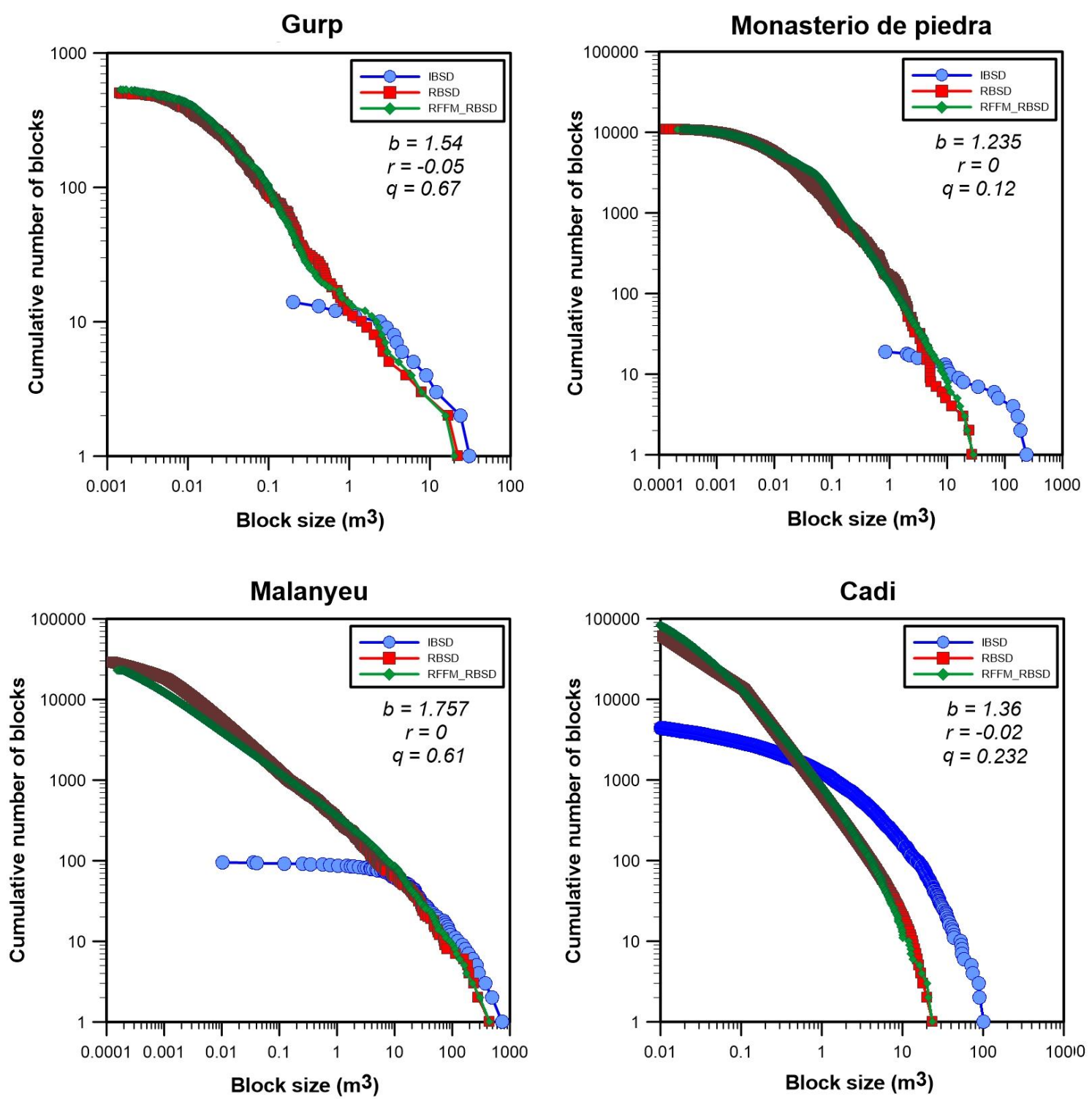

Figure 11: Application of the RFFM to the IBSD of Gurp, Monasterio de Piedra, Malanyeu and Cadí rockfall events and the simulated (RFFM_RBSD) and measured (RBSD) fragment distributions.

The size distribution of the fragments shows scale variant patterns. The biggest fragments are often the strongest ones, and their volumes approach the size of the biggest blocks of the initial distribution. The curves of the volume distribution of the largest fragments of the RBSD and RFFM are substantially parallel and very close to the curve of the IBSD, in all the cases. It is also interesting the change in the slope of the distributions for the smallest fragments. The relation tends to flatten, evolving from a power law to an exponential curve (Figure 11). Two possible explanations may be proposed for such a behavior: the undersampling of the small-size fragments, or the change of the pattern of breakage of the particles. Undersampling has been claimed as the cause for the deviation of the distribution of landslides and rockfalls from the power law (Evans \& Hungr 1993). 
Editorial version: https://link.springer.com/article/10.1007/s00603-019-01987-2

In this case, this possibility has to be disregarded because, as shown in Table 1, the flattening of the curve initiates at fragment sizes several orders of magnitude larger that the smallest fragment size measured. Therefore, the flattening of the curve might reflect a change in the fragmentation pattern associated to the reduction of the particle size. As fragments become smaller than the joint spacing, fragmentation requires the breakage of the rock matrix.

The model calibrated parameters are summarized in Table 4. In all the cases, the $\mathrm{Xi}_{\mathrm{r}}^{2}$ ranges between 0.0004 and 0.018 . Notice that the values of the geometric factor " $b$ " range between 1.235 and 2.34 , and the probability of survival " $q$ " between 0.18 and 0.9 . The parameter " $r$ ", yields 4 cases where it is equal to 0 (Table 4 ), characterizing these rockfall events as a predominant invariant behavior.

The fractal dimensions for the scale variant cases vary between a minimum and a maximum value (Dmin and Dmax in Table 4), as well as the probability of failure (Pmin and Pmax in Table 4), depending on the probability of survival " $q$ ", the exponent " $r$ ". In scale variant formulation, the fractal dimensions and the probability of failure vary for each iteration. In the numerical solution, the fractal dimensions vary for each " $\mathrm{n}$ " fragment generated, due to the " $\mathrm{b}$ " " term is replaced by " $\mathrm{b}$ ". For these reason, in scale variant formulation, each new fragment generated uses a different value of the fractal dimensions, that can be plotted as a distribution or described by the maximum and the minimum values used.

Table 4: Summary of the model parameters calibrated and measured errors.

\begin{tabular}{ccccccccccc} 
Rockfall & $\mathbf{b}$ & $\mathbf{r}$ & $\mathbf{q}$ & $\mathbf{D m i n}$ & $\mathbf{D m a x}$ & $\mathbf{P m i n}$ & $\mathbf{P m a x}$ & $\mathbf{X i}_{\mathbf{r}}{ }^{2}$ & $\begin{array}{c}\mathbf{V} \min \\
\left(\mathbf{m}^{\mathbf{3}}\right)\end{array}$ & $\begin{array}{c}\text { Fine fraction } \\
\left(\mathbf{m}^{\mathbf{3}}\right)\end{array}$ \\
\hline 1.PdG & 2.34 & -0.1 & 0.9 & 0.19 & 1.224 & 0.17 & 0.30 & 0.0001 & 0.0001 & $4.28 \mathrm{E}-08$ \\
2.Omells & 1.76 & 0 & 0.52 & 1.701 & 1.701 & 0.48 & 0.48 & 0.0061 & 0.0007 & 0.00034 \\
3.Lluçà & 1.9 & 0 & 0.77 & 0.710 & 0.710 & 0.23 & 0.23 & 0.0180 & 0.0007 & 0.038 \\
4.Gurp & 1.54 & -0.05 & 0.67 & 0.382 & 2.219 & 0.34 & 0.34 & 0.0054 & 0.0015 & 0.1 \\
5.MdP & 1.235 & 0 & 0.18 & 2.169 & 2.169 & 0.82 & 0.82 & 0.0048 & 0.001 & 62 \\
6.Malanyeu & 1.757 & 0 & 0.61 & 1.322 & 1.330 & 0.39 & 0.39 & 0.0049 & 0.0015 & 10 \\
7.Cadi & 1.36 & -0.02 & 0.23 & 2.121 & 2.465 & 0.77 & 0.88 & 0.0022 & 0.01 & 489
\end{tabular}




\section{Discussion}

\subsection{Number of fragments}

The number of fragments generated is relevant in quantitative risk analysis because it affects the probability of impact. Given the uncertainties of the quantification of the persistence of the joints, the number of initial blocks of the IBSD has to be considered a rough estimation. On the contrary, the total number of fragments generated is well constraint by the in-situ measurements. Figure 12 (left) presents the number of blocks of the IBSD (blue circles), the number measured fragments (red diamonds), and the number of modeled fragments (green squares). The vertical displacement from the IBSD to both the RBSD and the RFFM shows the increase of blocks in each rockfall by breakage. The total number of fragments increases as the rockfall volume increases, as expected. To highlight the effect of fragmentation, Figure 12 (right) shows the number of blocks normalized by the rockfall volume. The normalized number of fragments ranges between 5 and $10 \mathrm{blocks} / \mathrm{m}^{3}$ for event volumes smaller than $100 \mathrm{~m}^{3}$, except in the Pont de Gulleri case, with 45 blocks $/ \mathrm{m}^{3}$. In the latter case, the original rock mass is a densely fractured metamorphic rock and the initial number of blocks exceeds $10 \mathrm{blocks} / \mathrm{m}^{3}$.

Total $\mathrm{n}^{\circ}$ of fragments - Rockfall Volume

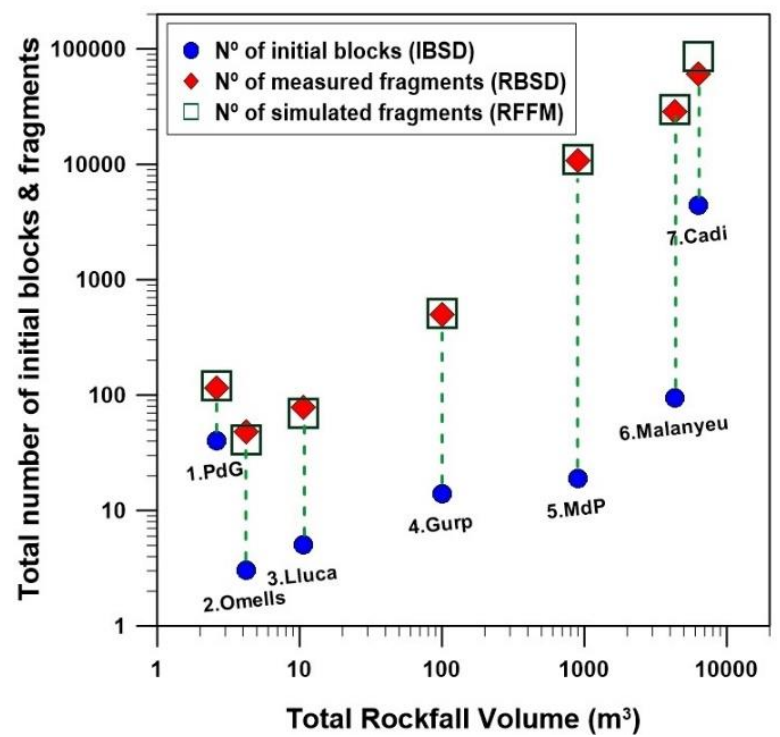

Normalized $\mathrm{n}^{\circ}$ of blocks

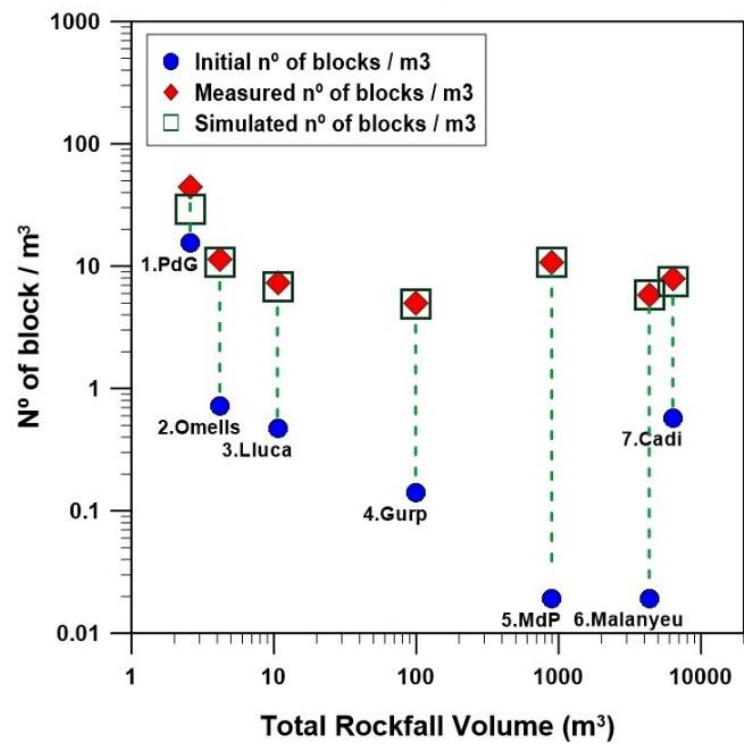

Figure 12: Left: Total number of initial blocks (of the IBSD, blue dots), fragments measured (red dots) and modeled fragments (green squares); Right: number of fragments normalized by the rockfall volume. 


\subsection{Probability of survival}

The parameter " $q$ " controls the proportion of the initial block that remains after the breakage. It defines the largest fragment " $l_{\max }$ " remaining after the impact. In the presented calibration exercise, the same set of model parameters is used for all the blocks for each rockfall event. Some trends may be derived from the results. The cases of Cadí and MdP stand out above the rest, showing remarkably low values of the probability of survival " $q$ ", indicating that the initial blocks are significantly reduced in size. These two events are characterized for their large volume and free fall height (50 and $35 \mathrm{~m}$, respectively, Table 2), suggesting that the impact energy must have an effect on it. On the opposite end, PdG and Lluçà display the highest " $q$ " values indicating limited block fragmentation. The latter mobilized small volumes and fell from a reduced free fall height.

Therefore, the results of Table 4 should be interpreted in light of both the probability of survival and the number of new fragments created by the impact. Thus, despite the probability of survival of Omells (0.52) is smaller than in Gurp (0.67) and Malanyeu (0.61), in the latter two, the number of new generated fragments has increased up to two order of magnitude and reaching similar normalized number of fragments (Figure 12, right), which indicates more intense fragmentation. These figures are approximate values only because the fine fraction is not included in the plots.

According to the equation 7, the model parameters, " $q$ " and " $b$ ", relate to the Fractal Fragmentation Dimension. However, as shown in Figure 13 left, the relation is weak. Comparing the model parameters with some rock mass properties, the RMR (Bieniawski, 1979) shows a very weak positive correlation with the geometric factor " $b$ " and with the probability of survival (Figure 13 right). Similarly occurs with the correlation with the Uniaxial Compressive Strength (UCS) and the Tensile Strength (TS) (Figure 14), where no clear correlations are found.
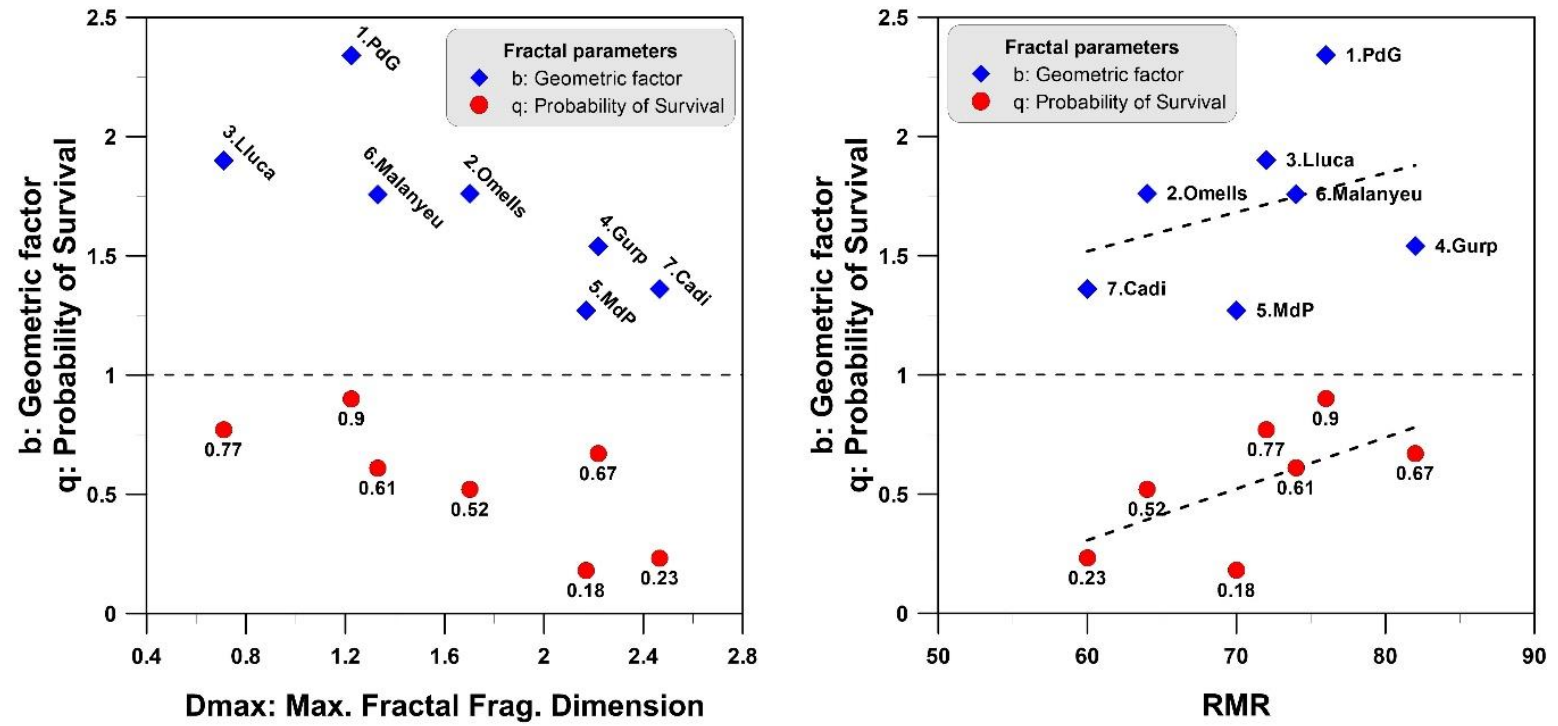

Figure 13: Calibrated model parameters " $b$ " and " $q$ " versus Max. Fractal Fragmentation Dimension (left) and Rock Mass Rating, RMR (right). 

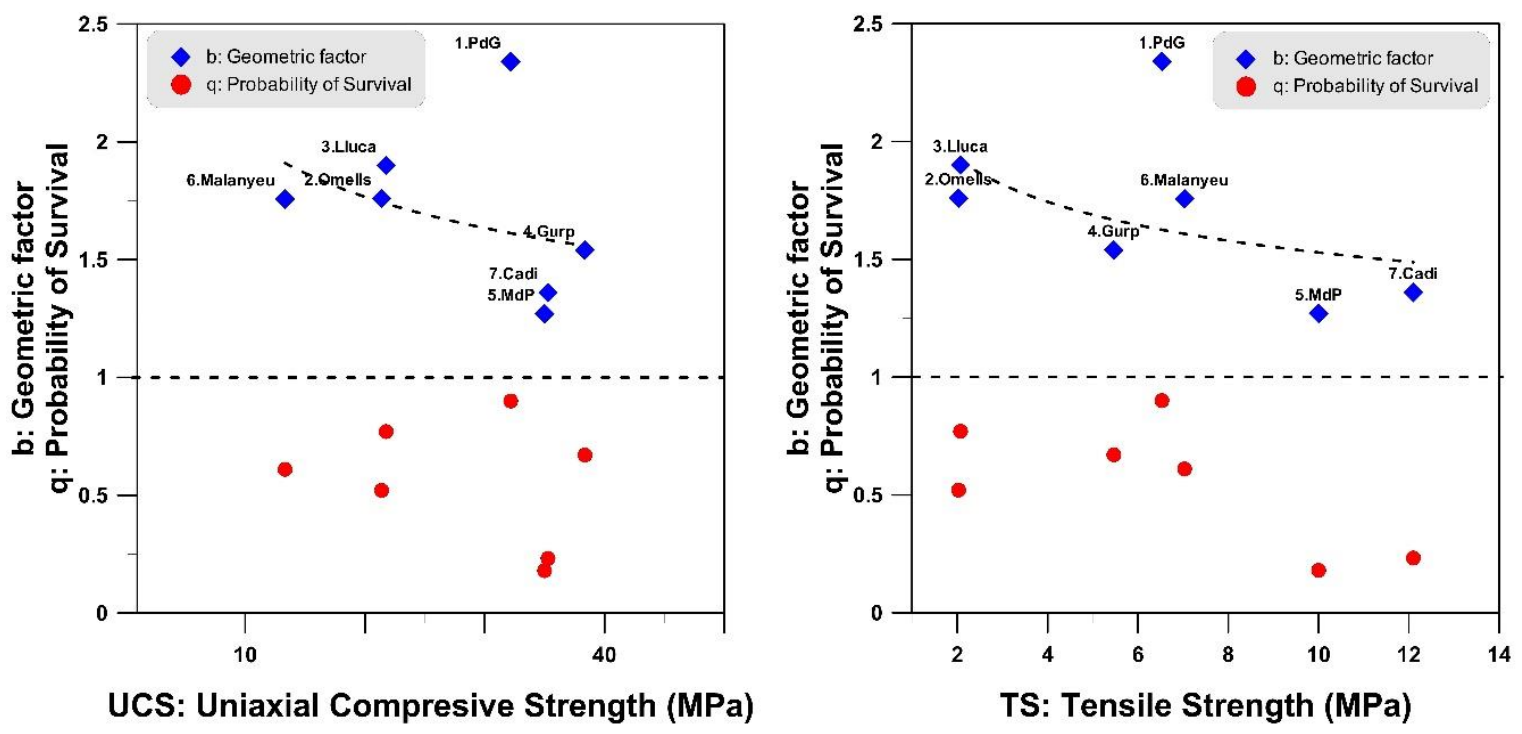

Figure 14: Calibrated model parameters " $b$ " and " $q$ " versus Uniaxial Compressive Strength (left) and Tensile Strength (right).

The lack of direct correlation between fragmentation and rock strength parameters in already known. In fact, real scale tests carried out with relatively homogeneous rocks and similar setting have shown high scattering of the results (Giacomini et al. 2009; Gili et al. 2016). Fragmentation is a complex physical process. Many parameters contribute to fragmentation such as the presence of discontinuities and/or fissures in the impacting rock, the strength of the rock, the impacting energy, the rigidity of ground conditions, impact angle and velocity (Dussage et al. 2003; Wang and Tonon, 2010). This complexity cannot be visualized be means of bivariate correlations. 
Editorial version: https://link.springer.com/article/10.1007/s00603-019-01987-2

\subsection{Newly generated surfaces and impact energy}

The energy required to break the rock blocks has been related to amount of the new area created (Bond 1952, Locat et al, 2006, Crosta et al 2007). We have calculated the increase of blocks' surface area associated to fragmentation in the inventoried rockfall events. First, we listed the 3D surface areas of the blocks in the IBSD, and we sum them all to obtain the total Initial Area $\left(\mathrm{IA}_{3 \mathrm{D}}\right)$ of the detached rock mass. We also calculate the equivalent surface area of cubes having the same volume than the blocks of the IBSD (IA $\left.\mathrm{A}_{\text {cubic }}\right)$ using the following expression:

$$
\mathrm{IA}_{\text {cubic }}=6 \mathrm{~V}^{2 / 3} \quad \text { Eq. } 9
$$

The reason for calculating the cubic area is that usually the data collected in rockfall inventories are the list of volumes, not the areas. The results of Figure 15 show that $\mathrm{IA}_{3 \mathrm{D}}$ (light blue columns) is bigger than $\mathrm{IA}_{\text {cubic }}$ (dark blue columns).

The Total Area (TA) is the total surface area of the fragments calculated from the RFFM simulation (TA RFFM $)$ or based on the measured RBSD list of volumes (TARBSD) (Figure 15, green and red columns, respectively). We measured in the field 3 lengths $\left(d_{1}, d_{2}, d_{3}\right)$ of each rock fragment to calculate the total surface area assuming prismatic and cubic shapes (Table 5). As there is no significant difference between the prismatic and the cubic estimation, the latter was used to calculate the area of the RBSD.

Table 5: Surface area of the fragments calculated from the measurement of three fragment dimensions $\left(\mathrm{d}_{1}, \mathrm{~d}_{2}\right.$, $d_{3}$ ) assuming prismatic shape and the equivalent cubic shape:

\begin{tabular}{ccccc} 
Rockfall & $\begin{array}{c}\text { Prismatic }\left(\mathbf{m}^{\mathbf{2}}\right) \\
A_{p}=2 d_{1} d_{2}+2 d_{1} d_{3}+2 d_{2} d_{3}\end{array}$ & $\begin{array}{c}\text { Cubic }\left(\mathbf{m}^{\mathbf{2}}\right) \\
A_{c}=6 V^{2 / 3}\end{array}$ & $\begin{array}{c}\text { Difference }\left(\mathbf{m}^{\mathbf{2}}\right) \\
D=A_{p}-A_{c}\end{array}$ & $\begin{array}{c}\text { \% Diff } \\
D \%=100 \cdot D / A_{p}\end{array}$ \\
\hline 1.PdG & 45.95 & 42.59 & 3.36 & $7.31 \%$ \\
2.Omells & 45.95 & 43.99 & 1.96 & $4.27 \%$ \\
3.Lluçà & 63.49 & 58.39 & 5.1 & $8.03 \%$ \\
4.Gurp & 627.51 & 591.85 & 35.66 & $5.68 \%$ \\
5.MdP & 1668 & 1596 & 72 & $4.32 \%$ \\
6.Malanyeu & 11328 & 10880 & 448 & $3.95 \%$ \\
7.Cadi & 2991 & 2936 & 55 & $1.84 \%$
\end{tabular}

As shown in Figure 15 the fragmentation model reproduces satisfactorily the TA, being the $\mathrm{TA}_{\mathrm{RBSD}}$ (red column) and the $\mathrm{TA}$ RFFM (green column). 


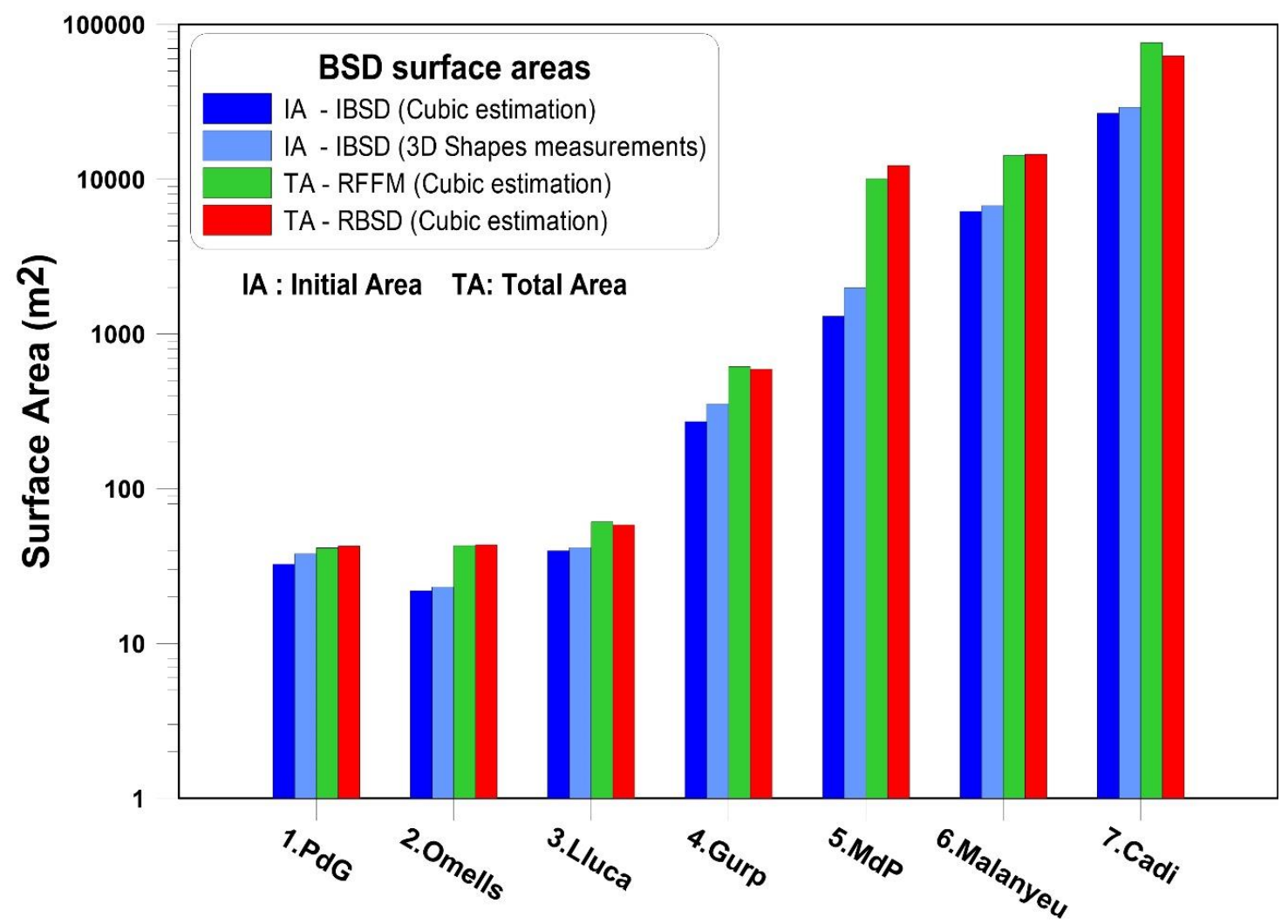

Figure 15: Surface areas calculated: Initial surface area (IA) from the IBSD using a cubic estimation (dark blue) or from $3 \mathrm{~d}$ shapes of the blocks modeled (light blue bar); Total surface area of the fragments generated (TA) from RFFM and RBSD (green and red bars respectively); using a cubic estimation

The difference between the $\mathrm{IA}_{\text {cubic }}$ (blue surface in Figure 16) and the TA (using TA $\mathrm{A}_{\mathrm{RBSD}}$ or TA $\mathrm{A}_{\mathrm{RFFM}}$, both cubic estimations (red surfaces in Figure 16), yields the new surface area (NA) generated by breakage (orange surface in Figure 16), defined as: $N A_{R B S D}=T_{A} A_{R B S D}-I A_{\text {cubic }}$ and $N A_{R F F M}=T A_{R F F M}-I A_{\text {cubic }}$. A very good correlation is found by fitting a power law to the total volume of the rockfall (Figure 17, left). The coefficients of determination $r$-squared are 0.971 for the $\mathrm{NA}_{\mathrm{RFFM}}$ and 0.96 for the $\mathrm{NA}_{\mathrm{RBSD}}$.

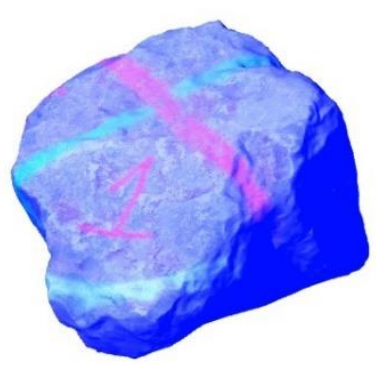

Initial Area

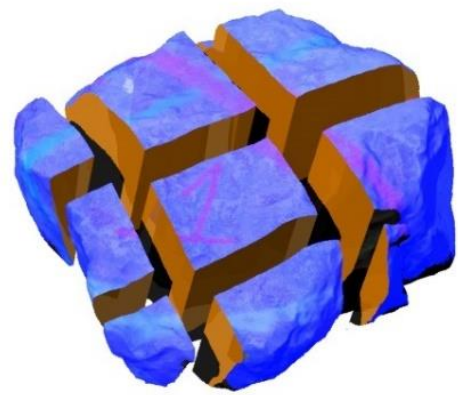

New Area $\mathbf{=}$ Total Area $\boldsymbol{-}$ Initial Area

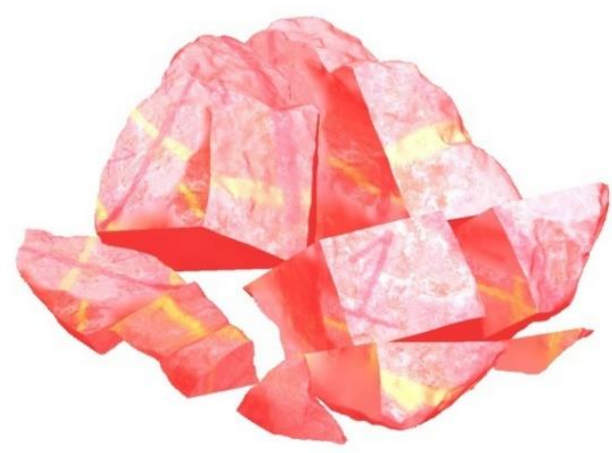

Total Area

Figure 16: Conceptual scheme of 3D surfaces in a single block breakage; Initial Area, Total Area, and the New Area generated by breakage and estimated by the difference of the Total Area minus the Initial Area. 
Editorial version: https://link.springer.com/article/10.1007/s00603-019-01987-2

Spreafico et al (2017) and Blasio \& Crosta (2016) found a relation between the new surface area generated (NA) and the fragmentation energy. This is confirmed in Figure 17 right, the total potential energy of the rockfall event and the potential energy of the first impact on the ground are plotted against the new surface area created. A power law can be fitted with coefficients of determination r-squared of 0.96 (based on total potential energy) and 0.90 (based on the first impact potential energy), both cases using the $\mathrm{NA}_{\mathrm{RFFM}}$.
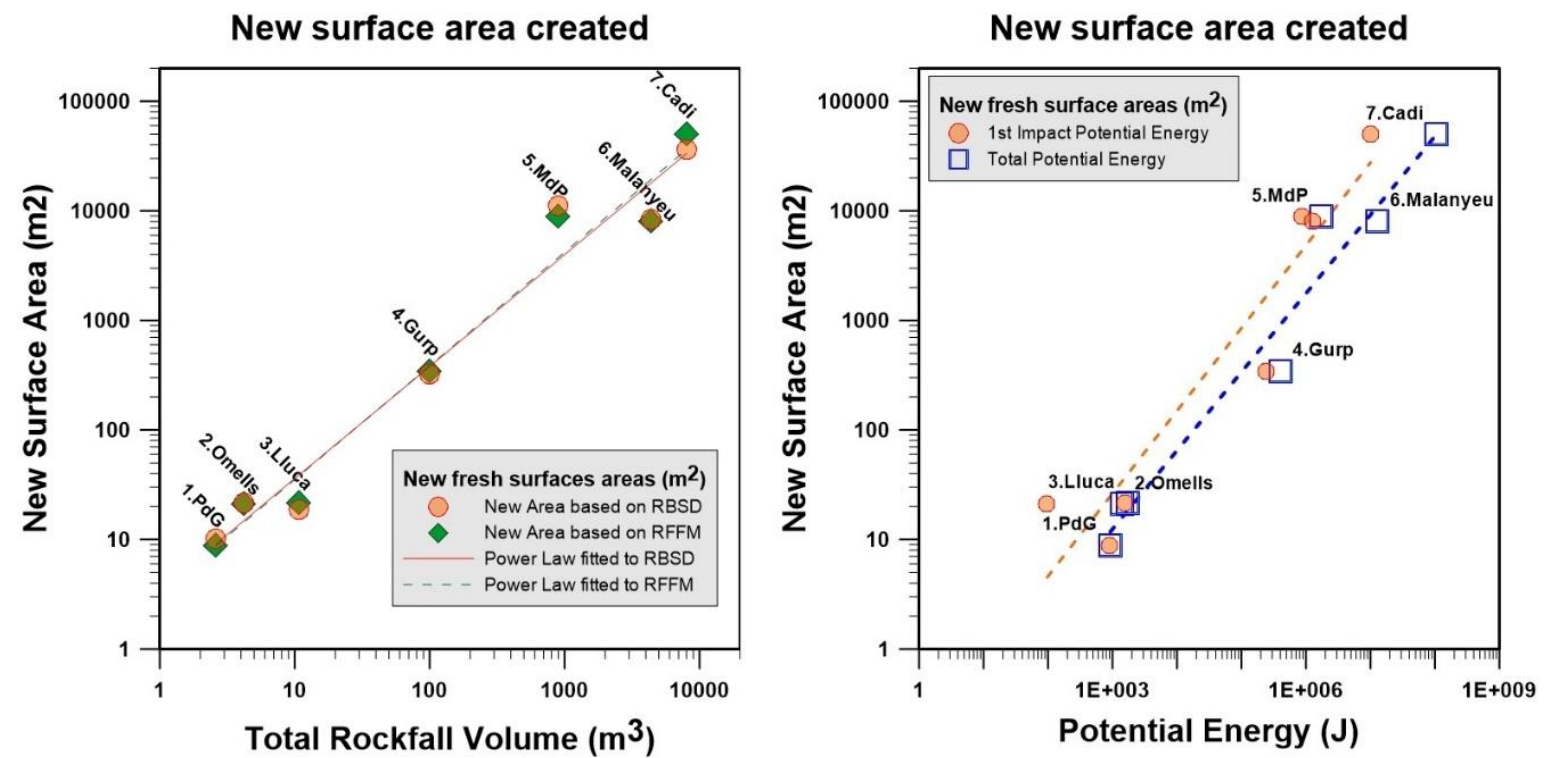

Figure 17: Left: New surface area from RBSD (NA $\mathrm{RBSD})$ or from RFFM (NA $\mathrm{RFFM})$ versus Total rockfall volume.

Right: New surface area $\left(\mathrm{NA}_{\mathrm{RFFM}}\right)$ versus Total Potential Energy and the 1st Impact Potential Energy.

The Specific Surface Area (SSA) is a property of solids defined as the total surface area per unit volume $\left(\mathrm{m}^{2} / \mathrm{m}^{3}\right.$ or $\mathrm{m}^{-1}$ ). The total surface areas IA, TA and NA have been normalized by the rockfall volume, obtaining: the Initial Specific Surface Area (ISSA) representing the initial state in the cliff, the Total Specific Surface Area (TSSA) representing the deposited fragments, and the New Specific Surface Area (NSSA) representing the new surfaces related with the breakage, (Table 6). 
Editorial version: https://link.springer.com/article/10.1007/s00603-019-01987-2

Table 6: Initial Specific Surface Area (ISSA), Total Specific Surface Area (TSSA); New Specific Surface Area (NSSA); the proportion of NA over TA in percentage (equal to NSSA/TSSA); and the Increase Area ratio.

\begin{tabular}{|c|c|c|c|c|c|}
\hline Rockfall & ISSA & NSSA & TSSA & $\mathbf{N A} / \mathbf{T A}$ & $\begin{array}{c}\text { Increase Area } \\
\text { ratio } \\
\text { TA / IA }\end{array}$ \\
\hline & $\begin{array}{c}\text { Initial Area / } \\
\text { Total volume } \\
\left(\mathbf{m}^{\mathbf{2}} / \mathbf{m}^{\mathbf{3}}\right)\end{array}$ & $\begin{array}{c}\text { New Area / } \\
\text { Total volume } \\
\left(\mathbf{m}^{\mathbf{2}} / \mathbf{m}^{3}\right)\end{array}$ & $\begin{array}{c}\text { Total Area } / \\
\text { Total Volume } \\
\left(\mathbf{m}^{\mathbf{2}} / \mathbf{m}^{\mathbf{3}}\right)\end{array}$ & $(\%)$ & - \\
\hline 1.PdG & 12.5 & 3.4 & 15.9 & 21 & 1.27 \\
\hline 2.Omells & 5.2 & 5.0 & 10.2 & 49 & 1.95 \\
\hline 3.Lluca & 3.7 & 2.0 & 5.7 & 35 & 1.54 \\
\hline 4.Gurp & 2.7 & 3.4 & 6.1 & 56 & 2.26 \\
\hline 5.MdP & 1.3 & 8.8 & 10.1 & 87 & 5.09 \\
\hline 6.Malanyeu & 1.3 & 1.6 & 2.9 & 56 & 2.29 \\
\hline 7.Cadi & 3.5 & 6.5 & 10.0 & 65 & 2.86 \\
\hline
\end{tabular}

Figure 18 (left) shows the ISSA (in blue), the NSSA (stacked in orange) and the TSSA (adjacent column in red). Also the proportion of NA/TA (or NSSA/TSSA) is plotted as a percentage. The ISSA column represents the initial surfaces per volume unit, defining the initial degree of fracturing of the rock mass. NSSA quantify the new area created by breakage. The vertical bars (Figure 18 left) represent the proportion between disaggregation (previously existing surfaces) and breakage (new surfaces). The increase of area due to breakage results in an Increase Area Ratio, defined as the total area (TA) over the initial area (IA). Figure 18 (right) shows the trend of the Increase Area Ratio with the model parameters.
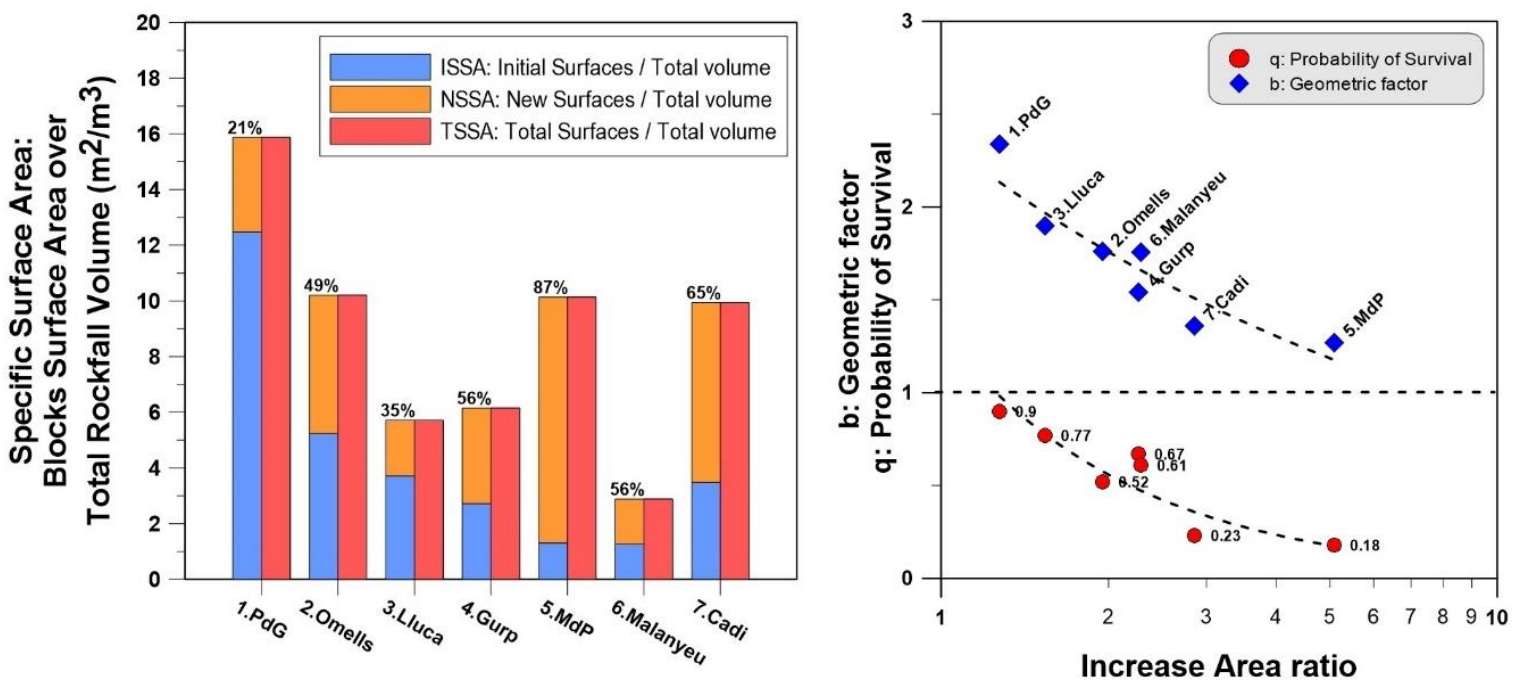

Figure 18: Left: Initial, New and Total Specific Surface Area (ISSA, NSSA and TSSA). Left bar stacks the ISSA (in blue, from IBSD) and the NSSA generated by breakage (in orange, with the percentage that represent over the TSSA labelled on the top). Right bar represents the TSSA representing the deposited blocks (in red, from RBSD). Right: Model parameters versus Increase Area ratio. 
Editorial version: https://link.springer.com/article/10.1007/s00603-019-01987-2

Pont de Gulleri (PdG) shows the highest value of TSSA, however, only the $21 \%$ of the surface is new and related to breakage. $79 \%$ of the surfaces were already present in the detached rock mass as shown by the ISSA value of $12.5 \mathrm{~m}^{2} / \mathrm{m}^{3}$. In this case, fragmentation is governed by the disaggregation of the rock mass along preexisting discontinuities.

Monasterio de Piedra (MdP), Cadi and Omells events show TSSA values close to $10 \mathrm{~m}^{2} / \mathrm{m}^{3}$ with a variable proportion of newly generated surfaces: $87 \%, 65 \%$ and $49 \%$ respectively, being Monasterio de Piedra the event with the highest breakage ratio, followed by the Cadi case. These high NA/TA ratios may be explained by the high free fall heights and the potential energy (Figure 17, right). In contrast, rockfalls of Lluçà, Gurp and Malanyeu show low values of TSSA and are interpreted as low fragmentation events. In the latter group of events, a number of blocks remain intact or slightly broken only: Lluçà includes a block of $8,5 \mathrm{~m}^{3}$ over $10,7 \mathrm{~m}^{3}$ of total detached mass; Gurp includes two blocks of more than $20 \mathrm{~m}^{3}$ over the total $100 \mathrm{~m}^{3}$ of rockfall; and Malanyeu, where the deposit includes 7 blocks greater than $100 \mathrm{~m}^{3}$, with a maximum boulder of $445 \mathrm{~m}^{3}$, and more than 60 blocks bigger than $10 \mathrm{~m}^{3}$.

The model parameters show a trend with the NA (Figure 19, right) and a distinct correlation with the proportion of NA/TA (Figure 19, left). By decreasing the geometric factor " $b$ " and the probability of survival " $q$ ", the NA/TA increase, increasing the proportion of new fresh faces by breakage.
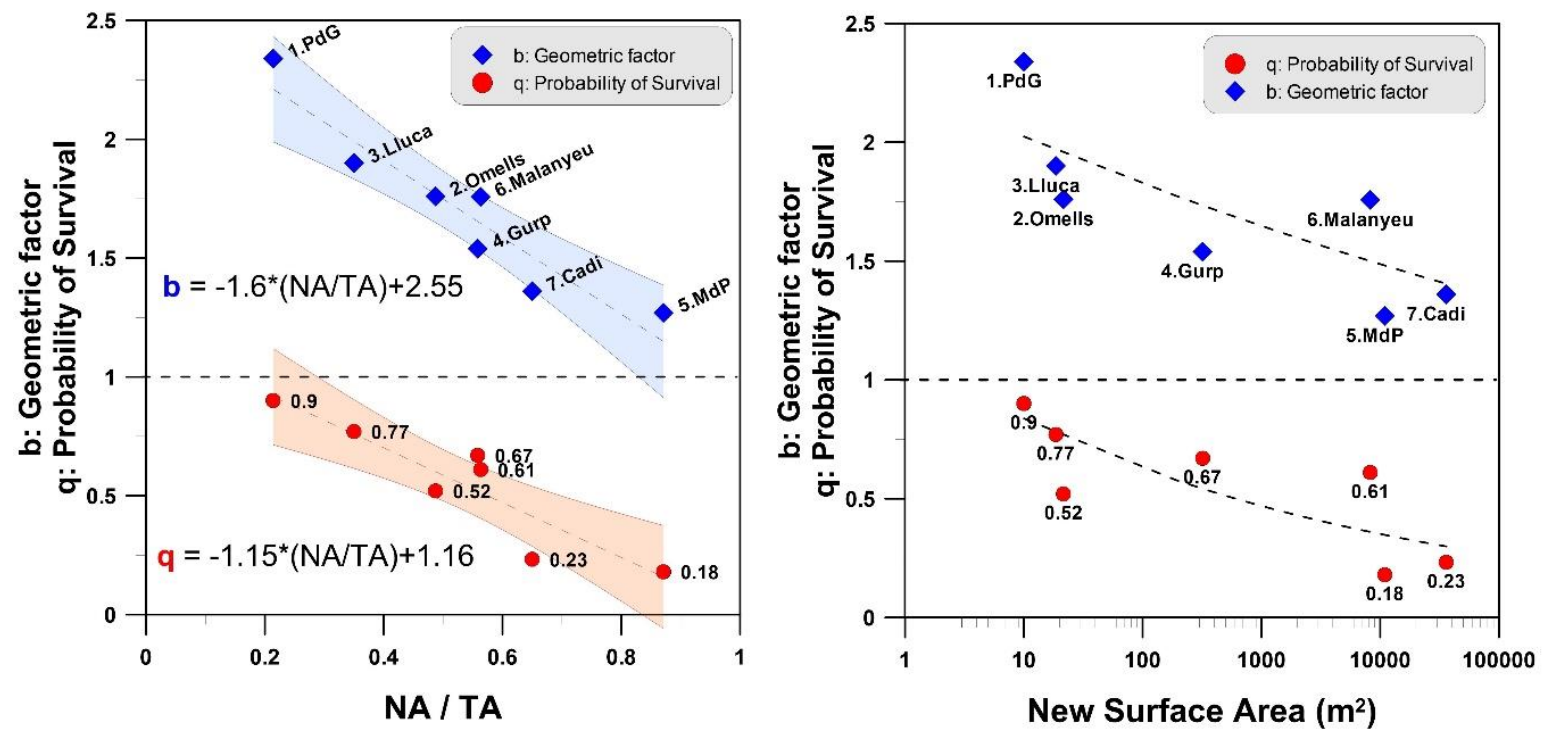

Figure 19: Model parameters " $b$ " and " $q$ " versus the proportion of New Area over the Total Area (NA/TA, left), and versus New Surface Area created, (NA, right). 
Editorial version: https://link.springer.com/article/10.1007/s00603-019-01987-2

\subsection{Model applicability}

Fragmentation is a stochastic phenomenon. Further parametric analyses and calibration exercises are needed before providing guidance for the performance of the RFFM and its implementation in rockfall hazard assessment. Despite of this limitation, our results show that fragmentation scenarios in which the size of the potentially unstable rock mass and the impact height are estimated beforehand, can be simulated using a range of initial model parameters. This is exemplified in Figure 20. A potentially unstable rock mass is identified in a cliff. The rock mass is characterized by its volume and the IBSD.

A preliminary trajectographic analysis may provide the most likely impact point within confidence limits, from which estimate the potential energy (Ep) of the first impact and a first estimation of the new area generated by fragmentation (Figure 17 right and Figure 20). The ratio NA/TA is then obtained from the following expression:

$$
\frac{N A}{T A}=\frac{N A}{N A+I A} \quad \text { Eq. } 10
$$

Being all the parameters known at this stage. The model parameters " $b$ " and " $q$ " may be estimated (with a range of confidence or introducing a random variation in a defined range) using Figure 20 bottom. The fractal dimension (D) and $1_{\max }$ are finally estimated from Eqs. 7 and 8, respectively. The main equation (Eq.5) of the RFFM may be used to generate a distribution of fragments until the sum of the fragments reach the initial block volume or until the new fragments generated become smaller than the minimum volume defined. The scalevariant behavior is controlled with parameter " $\mathrm{r}$ " and may be considered equal to 0 as a first approach. 

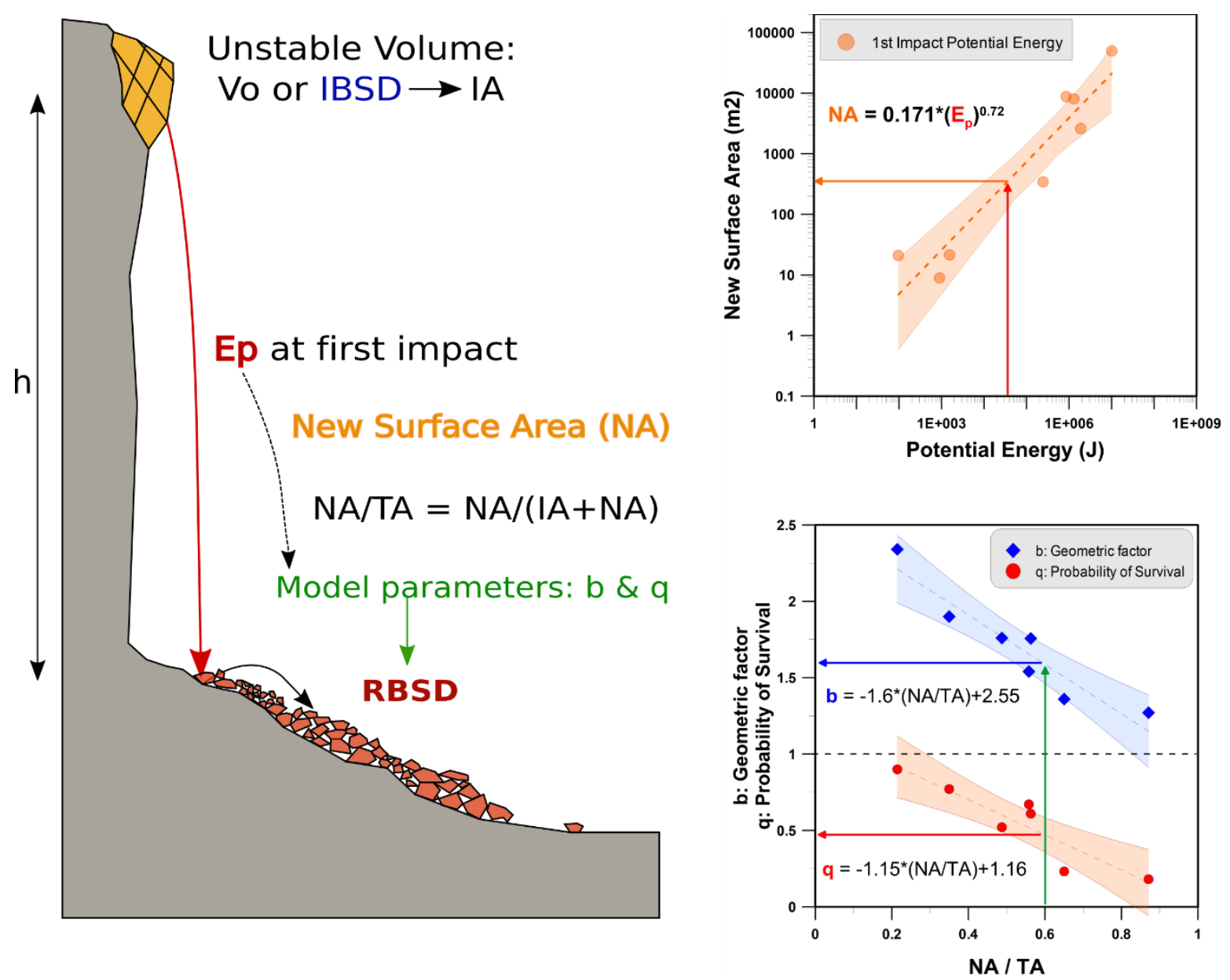

Fig. 20: Framework for the implementation of the RFFM.

\section{Conclusions}

Perfect (1997) highlights the importance of describing the initial state of a brittle material before and after the fragmentation to study properly the phenomenon. UAV and digital photogrammetric techniques were used to obtain detailed 3D models of the whole scenario, and specifically, of the scar. From the latter, it is possible to reconstruct the detached volume and characterize the joint pattern. We used the real position of the modelled joints to generate the DFN, assuming infinite persistence, as hypothesis (as a first approach). The reconstructed volume is cut in order to estimate the IBSD. We inventoried 7 rockfalls with total volumes ranging between 2.6 $\mathrm{m}^{3}$ and $10.000 \mathrm{~m}^{3}$, measuring more than 7200 fragments of the deposits (3 lengths with a tape assuming prismatic shape) in order to obtain the RBSD of each inventoried rockfall event. Using the IBSD as input, and the measured RBSD, we calibrate the model parameters to simulate the RBSD and the estimation of the new surfaces created. The model is able to reproduce satisfactorily the measured RBSD, from the IBSD. 
Editorial version: https://link.springer.com/article/10.1007/s00603-019-01987-2

In order to simulate all possible rockfall scenarios, the model has been upgraded, introducing two main improvements:

1) Avoidance of bins, working in cumulative form and preserving the mass balance: With the use of bins, all the fragments from each size bin in the IBSD is defined by an average size, and the fragments created on each iteration are equal size. Due to this, the mass balance cannot be guaranteed. The upgraded model uses each initial block of the IBSD (list of volumes) as initiator, and generates an accumulated number of fragments of decreasing size that fits better to the observations, specially in the case of a single block as initiator like in the real-scale fragmentation test on quarry. The model generates fragments until the sum of fragments is equal to the initiator initial volume, or until the fragments become smaller than a threshold value. The remaining mass is computed as volume of fine fragments (finer than the threshold defined). Thus, the upgraded model preserves mass balance.

2) The use of the scale-variant behavior: Based on the RBSD measured in the deposits and from the block size distributions measured in real-scale fragmentation tests, a scale-variant (or scale-dependent) behavior is observed. The upgraded model uses the formulation proposed by Perfect (1997) for scale-variant fragmentation. The probability of failure is defined by the probability of survival " $q$ ", and represents the largest remaining part of the block normalized by the initial block volume. The probability of survival controls whether a block breaks or not, being 1 for unbroken blocks. Here, the " $q$ " is applied over each initiator instead to the global number of initial blocks. Then, a new parameter " $r$ " controls scale dependency making blocks either stronger or weaker by decreasing their size. This happens when the fragment size is smaller than the minimum joint spacing or weakness planes within the rock mass. The upgraded model is able to reproduce all kind of block size distributions observed in natural rockfall deposits and of real-scale fragmentation test, even when the initiator is a single block.

In this study, we calibrate the model parameters using the same set of parameters " $b$ ", " $r$ " and " $q$ " for all the blocks of each rockfall event. The calibrated values of the geometric factor " $b$ " range between 1.235 and 2.34, and the probability of survival " $q$ " from 0.18 to 0.9 . The parameter " $r$ " controls the variant or invariant behavior, yields 4 cases where it is equal to 0 , characterizing these rockfall events as a predominant invariant behavior. In all the cases, the $\mathrm{Xi}_{\mathrm{r}}{ }^{2}$ used to calibrate the model ranges between 0.0004 and 0.018 . We use the average parameters of the fragmentation model, despite the fact that the set of parameters can be specific of each block, depending on the impact conditions. Future trajectory simulators considering fragmentation should be able to apply a different set of parameters for each block at each impact. A better understanding of factors controlling fragmentation is required and this will be the focus of our future research. In particular, the rigidity of the ground surface, which despite its relevance is difficult to quantify, as well as the impact conditions (impact angle), and both the shape and strength of the blocks. 
Editorial version: https://link.springer.com/article/10.1007/s00603-019-01987-2

The RMR shows a positive correlation with probability of survival " $q$ ", however, the correlation with the geometric factor " $b$ " is weak. Similarly occurs with the correlation with the Uniaxial Compressive Strength and the Tensile Strength without any direct correlation with the model parameters. It may be noticed a relation between the 3D surface area of the scar and the total rockfall volume, as well as the number of fragments and new area created in a wide range of orders of magnitude. The new area created is related to the fragmentation energy, and it appears directly correlated with the total rockfall volume as well as the total potential energy.

We propose the initial specific surface area (ISSA) and the specific area of the resultant fragments (TSSA) as quantitative descriptors of fragmentation. The ISSA (Initial Specific Surface Area) is the one generated by disaggregation of the rock mass through the preexisting discontinuities, and is defined by the IBSD. The NSSA (New Specific Surface Area) is the result of the breakage of the rock that creates new surfaces. According to this, the rockfall fragmentation may be characterized by the proportion of New Surface Area over Total Surface Area (NA/TA = NSSA/TSSA). The model parameters show a strong correlation with the proportion of NA/TA and with the Increase Area ratio defined as TA/IA as alternative.

Finally, a relation has been observed between the potential energy of the first impact, the new surface area of fragments generated, and the model parameters. However, the number of inventoried cases is still small to generalize these findings. The fragmentation process is a complex phenomenon where randomness may affect the results. From real-scale fragmentation test, we observed that blocks dropped from the same height on the same place yield " $q$ " values ranging between 0.2 and 1 (unbroken) depending on the local impact conditions (Ruiz-Carulla et al. 2016b). For these reasons, a probabilistic approach of the fragmentation should still be used.

\section{Acknowledgments}

The authors acknowledge the support of the Spanish Economy and Competitiveness Ministry and the European Regional Development's funds (FEDER), to the Rockmodels research project (BIA2016-75668-P) and the support of the Ministry of Education to the first author (grant code FPU13/04252).

\section{Conflict of Interest}

R. Ruiz Carulla declares that he has no conflict of interest. J Corominas declares that he has no conflict of interest. 


\section{References}

Agliardi F, Crosta G, Frattini P (2009) Integrating rockfall risk assessment and countermeasure design by 3D modelling techniques Nat. Hazards Earth Syst. Sci., 9 , pp. 1059-1073 http://dx.doi.org/10.5194/nhess9-1059-2009.

Aler J, Du Mouza J, Arnould M (1996) Measurement of the Fragmentation Efficiency of Rock Mass Blasting and its Mining Applications. Int. J. Rock Mech. Min. Sci. \& Geomech. Abstr., 33: 125-139

Bakar MZ, Gertsch LS, Rostami J (2014) Evaluation of Fragments from Disc Cutting of Dry and Saturated Sandstone. Rock Mech Rock Eng, 47:1891-1903.

Bieniawski, Z.T. (1979) The Geomechanics Classification in Rock Engineering Application. Proceedings 4th International Congress on Rock Mechanics, Montreux, 2-8 September 1979, Vol. 2, 41-48.

Blasio F. V., Corsta G. B. (2016) Extermly Energetic Rockfall: Some Preliminar estimates. 12th International Symposium on Landslides (ISL 2016) Landslides and Engineered Slopes. Experience, Theory and Practice - Aversa et al. (Eds) () 2016 Associazione Geotecnica Italiana, Rome, Italy, ISBN 978-1-13802988-0.

Bonadona C, Houghton BF (2005) Total grain-size distribution and volume of tephra-fall deposits. Bull Volcanology 67:441-456. DOI 10.1007/s00445-004-0386-2.

Bond F C (1952) The third theory of comminution, Transactions of the American Institue of Mining and Metallurgical Engineers, 193. 494-495.

Bowman ET, Take AW (2015) The Runout of Chalk Cliff Collapses in England and France - Case Studies and Physical Model Experiments." Landslides, Volume 12 (2), pp: 225-239. doi: 10.1007/s10346-014$0472-2$.

Buyer A and Schubert W (2017) Calculation the Spacing of Discontinuities from 3D Point Clouds. Symposium of the International Society for Rock Mechanics. Procedia Engineering 191: 270 - 278. https://doi.org/10.1016/j.proeng.2017.05.181.

Charrière M, Humair F, Froese C, Jaboyedoff M, Pedrazzini A, Longchamp C (2015) From the source area to the deposit: Collapse, fragmentation, and propagation of the Frank Slide. Geological Society of America Bulletin. doi: 10.1130/B31243.1. 
Editorial version: https://link.springer.com/article/10.1007/s00603-019-01987-2

Corominas J., Matas G., Ruiz-Carulla R. (2019) Quantitative analysis of risk from fragmental rockfalls. Landslides. Volume 16, Issue 1, pp 5-21 DOI: 10.1007/s10346-018-1087-9.

Crosta GB, Frattini P, Fusi F (2007) Fragmentation in the Val Pola rock avalanche, Italian Alps. Journal of Geophysical Research, 112: p. F01006.

Crosta GB, Agliardi F, Frattini P, Lari S, Lollino G (2015) Key Issues in Rock Fall Modeling, Hazard and Risk Assessment for Rockfall Protection. Engineering Geology for Society and Territory, Volume 2, pp: 4358. DOI: 10.1007/978-3-319-09057-3_4.

Cunningham CVB (1987) Fragmentation estimations and Kuz-Ram model - four years on. Proceedings of second International Symposium on rock fragmentation by blasting, Keystone, Colorado, p.475-87.

Davies TR, McSaveney MJ, Hodgson KA (1999) A fragmentation-spreading model for long-runout rock avalanches. Canadian Geotechnical Journal, 36: 1096-1110.

Dewez T, Girardeau-Montaut D, Allanic C, Rohmer J (2016) Facets: A CloudCompare plugin to extract geological planes from unstructured 3d point clouds. XXIII ISPRS Congress, Jul 2016, Prague, Czech Republic. XLI-B5, pp.799-804, 2016, International Archives of the Photogrammetry Remote Sensing and Spatial Information Sciences.

Dorren LKA (2003) A review of rockfall mechanics and modeling approaches. Progress in Physical Geography 27 (1): 69- 87.

Dussauge C, Grasso JR, Helmstetter A (2003) Statistical analysis of rockfall volume distributions: Implications for rockfall dynamics. J Geophys Res B6 108: 2286.

Elmouti, MK, Poropat GV (2012). A Method to Estimate In Situ Block Size Distribution. Rock Mechanics and Rock Engineering, 45(3): 401-407.

Evans. S. Hungr. O. 1993. The assessment of rockfall hazard at the base of talus slopes. Canadian Geotechnical Journal 30:620-636.

Firpo, G., Salvini, R., Francioni, M., \& Ranjith, P. G. (2011). Use of Digital Terrestrial Photogrammetry in rocky slope stability analysis by Distinct Elements Numerical Methods. International Journal of Rock Mechanics and Mining Sciences, 48(7), 1045-1054. doi:10.1016/j.ijrmms.2011.07.007. 
Editorial version: https://link.springer.com/article/10.1007/s00603-019-01987-2

Gates WCB, Haneberg WC (2012) Comparison of Standard Structural Mapping Results to 3-D Photogrammetric Model Results : Boundary Transformer Banks Rockfall. American Rock Mechanics Association 12: 368 .

Gheibie S, Aghababaei H, Hoseinie S H, Pourrahimian Y (2009) Modified Kuz - Ram fragmentation model and its use at the Sungun Copper Mine. International Journal of Rock Mechanics \& Mining Sciences 46: 967-973. doi:10.1016/j.ijrmms.2009.05.003.

Giacomini A, Buzzi O, Renard B \& Giani, G P (2009) Experimental studies on fragmentation of rock falls on impact with rock surfaces. Int J Rock Mech Min Sci 46:708-715.

Gigli G, Casagli N (2011) Semi-automatic extraction of rock mass structural data from high resolution LIDAR point clouds. International Journal of Rock Mechanics and Mining Sciences. Volume 48, Issue 2, pp 187-198. https://doi.org/10.1016/j.ijrmms.2010.11.009

Gili JA, Ruiz-Carulla R, Matas G, Corominas J, Lantada N, Núñez MA, Mavrouli O, Buill F, Moya J, Prades A, Moreno S (2016) Experimental study on rockfall fragmentation: in situ test design and firsts results. In: Aversa S, Cascini L, Picarelli L, Scavia C (eds) Landslides and engineered slopes, 2: 983-990.

Girardeau-Montaut (2006) Detection de Changement sur des Données Géométriques 3D", D. PhD manuscript (french), Signal \& Images Processing, Telecom Paris.

Gong QM, Zhao J, Jiao YY (2005) Numerical modeling of the effects of joint orientation on rock fragmentation by TBM cutters. Tunnelling and Underground Space Technology, 20 (2): 183-191 doi.org/10.1016/j.tust.2004.08.006.

Haneberg WC, Norrish NI, Findley DP (2006) Digital Outcrop Characterization for 3-D Structural Mapping and Rock Slope Design along Interstate 90 near Snoqualmie Pass, Washington.” Proceedings 57th Annual Highway Geology Symposium, 1-14.

Hardin BO (1985) Crushing of soil particles. Journal of Geotechnical Engineering. Vol 111 Issue 10, pp 11771191.

Hartman, WK (1969) Terrestrial, lunar, and interplanetary rock fragmentation. Icarus, 10 (2): 201-213. doi.org/10.1016/0019-1035(69)90022-0. 
Editorial version: https://link.springer.com/article/10.1007/s00603-019-01987-2

Haug ØT, Rosenau M, Leever K, Oncken O (2016) On the energy budgets of fragmenting rockfalls and rockslides: Insights from experiments, J. Geophys. Res. Earth Surface, 121, 1310-1327, doi:10.1002/2014JF003406.

Hewitt K, (1999) Quaternary moraines vs catastrophic rock avalanches in the Karakoram Himalaya, Northern Pakistan. Quat. Res. 51, 220-237.

Hou, T., Xu, Q., Xie, H. Xu N, Zhou (2017) An estimation model for the fragmentation properties of brittle rock block due to the impacts against an obstruction. Journal of Mountain Science, Vol 14 (6), pages: 1161-1173. https://doi.org/10.1007/s11629-017-4398-8.

Hudaverdi T, Kuzu C, Fisne A (2010) Investigation of the blast fragmentation using the mean fragment size and fragmentation index. International Journal Rock Mechanics \& Minning Science, Volume 56, pp: 136-145. http://dx.doi.org/10.1016/j.ijrmms.2012.07.028.

Keil K, Haak H, Scott ERD (1994). Catastrophic fragmentation of asteroids: evidence from meteorites. Planetary and Space Science 42 (12): 1109-1122. DOI: 10.1016/0032-0633(94)90011-6.

Kulatilake PSHW, Qiong W, Hudaverdi T, Kuzu C (2010) Mean particle size prediction in rock blast fragmentation using neural networks. Engineering Geology, 114: 298-311 doi:10.1016/j.enggeo.2010.05.008.

Kuznetsov VM (1973). The mean diameter of fragments formed by blasting rock. Journal of Mining Science. 9: $144-148$.

Latham J, Meulen J, Dupray S (2006) Prediction of fragmentation and yield curves with reference to armourstone production. Engineering Geology 87: 60-74 doi:10.1016/j.enggeo.2006.05.005.

Locat P, Couture R, Leroueil S, Locat S (2006) Fragmentation Energy in Rock Avalanches. Canadian Geotechnical Journal 851 (20060135): 830-51. doi:10.1139/T06-045.

Lu P, Latham JP (1999). Developments in the assessment of in-situ block size distributions of rock masses. Rock Mechanics and Rock Engineering 32: 29-49. https://doi.org/10.1007/s006030050042.

Molnar P, Anderson RS, Anderson SP (2007) Tectonics, fracturing of rock, and erosion. Journal of Geophysical Research, 112, F03014, doi:10.1029/2005JF000433. 
Editorial version: https://link.springer.com/article/10.1007/s00603-019-01987-2

Morin MA, Ficarazzo F (2006) Monte Carlo simulation as a tool to predict blasting fragmentation based on the Kuz-Ram model. Computers \& Geosciences, 32: 352-359 doi:10.1016/j.cageo.2005.06.022.

Okura Y, Kitahara H, Sammori T, Kawanami A (2000) The effects of rockfall volume on runout distance. Engineering Geology 58(2):109-124.

Perfect E (1997) Fractal models for the fragmentation of rocks and soils: a review. Engineering Geology 48:185198.

Ruiz-Carulla R, Corominas J, Mavrouli O (2015) A Methodology to Obtain the Block Size Distribution of Fragmental Rockfall Deposits. Landslides 12 (4): 815-25. doi:10.1007/s10346-015-0600-7.

Ruiz-Carulla R., Corominas J, Mavrouli O (2016a). Comparison of block size distribution in rockfalls. Landslides and Engineered Slopes. Experience, Theory and Practice - Aversa et al. (Eds). pp. 17671774.

Ruiz-Carulla R., Matas G., Prades A., Gili J.A., Corominas J., Lantada N., Buill F., Mavrouli O., Núñez-Andrés M.A., Moya J. (2016b). Analysis of rock block fragmentation by means of real-scale tests. 3rd RSS Rock Slope Stability conference, Lyon 2016.

Ruiz-Carulla, R., Corominas, J. \& Mavrouli, O. Landslides (2017) A fractal fragmentation model for rockfall. Landslides 14 (3): 875-889. doi.org/10.1007/s10346-016-0773-8.

Sammis CG, King GCP (2007) Mechanical origin of power law scaling in fault zone rock. Geophysical Research Letters, 34. DOI: 10.1029/2006GL028548.

Sanchidrián JA, Ouchterlony F, Segarra P, Moser P (2014) Size distribution functions for rock fragments. International Journal of Rock Mechanics \& Mining Sciences, 71: 381-394.

Spreafico MC, Franci F, Bitelli G, Borgatti L, Ghirotti M (2017). Intact rock bridge breakage and rock mass fragmentation upon failure: quantification using remote sensing techniques. The Photogrammetric Record Vol 32, Issue 160: Pages 513-536 https://doi.org/10.1111/phor.12225.

Thiele ST, Grose L, Samsu A, Micklethwaite S, Vollgger SA, Cruden AR (2017) Rapid, semi-automatic fracture and contact mapping for point clouds, images and geophysical data. Solid Earth, 8: 1241-12535. 
Wang, Y, Tonon, F (2010) Discrete Element Modelling of Rock Fragmentation upon Impact in Rock Fall Analysis. Rock Mech Rock Eng 44: 23-35.

Weidinger JT, Korup O, Munack H, Alternberger U, Dunning SA, Tippelt G, Lottermoser W (2014) Giant rockslides from the inside. Earth and Planetary Science Letters 389: 62-73.

Wohletz, KH, Sheridan MF, Brown WK (1989) Particle size distributions and the sequential fragmentation/transport theory applied to volcanic ash. Journal of Geophysical Research: Solid Earth 94, B11 :15703-15721. doi.org/10.1029/JB094iB11p15703.

Zhao T, Crosta GB, Utili S, De Blasio FV (2017), Investigation of rock fragmentation during rockfalls and rock avalanches via 3-D discrete element analyses, J. Geophys. Res. Earth Surf., 122, 678-695, doi:10.1002/ 2016JF004060. 